\title{
Silver Nanoparticles as Colorimetric Sensors for Water Pollutants
}

\author{
Paolo Prosposito ${ }^{1}$, Luca Burratti ${ }^{1}$ and Iole Venditti ${ }^{2, * \mathbb{D}}$ \\ 1 Department of Industrial Engineering and INSTM, University of Rome Tor Vergata, Via del Politecnico 1, \\ 00133 Rome, Italy; paolo.prosposito@uniroma2.it (P.P.); luca.burratti@uniroma2.it (L.B.) \\ 2 Department of Sciences, Roma Tre University, via della Vasca Navale 79, 00146 Rome, Italy \\ * Correspondence: iole.venditti@uniroma3.it; Tel.: +39-06-5733-3388
}

Received: 5 March 2020; Accepted: 28 March 2020; Published: 31 March 2020

\begin{abstract}
This review provides an up-to-date overview on silver nanoparticles-based materials suitable as optical sensors for water pollutants. The topic is really hot considering the implications for human health and environment due to water pollutants. In fact, the pollutants present in the water disturb the spontaneity of life-related mechanisms, such as the synthesis of cellular constituents and the transport of nutrients into cells, and this causes long / short-term diseases. For this reason, research continuously tends to develop always innovative, selective and efficient processes / technologies to remove pollutants from water. In this paper we will report on the silver nanoparticles synthesis, paying attention to the stabilizers and mostly used ligands, to the characterizations, to the properties and applications as colorimetric sensors for water pollutants. As water pollutants our attention will be focused on several heavy metals ions, such as $\mathrm{Hg}(\mathrm{II}), \mathrm{Ni}(\mathrm{II}), \mathrm{Cu}(\mathrm{II}), \mathrm{Fe}(\mathrm{III}), \mathrm{Mn}$ (II), $\mathrm{Cr}(\mathrm{III} / \mathrm{V}) \mathrm{Co}$ (II) $\mathrm{Cd}(\mathrm{II}), \mathrm{Pb}$ (II), due to their dangerous effects on human health. In addition, several systems based on silver nanoparticles employed as pesticides colorimetric sensors in water will be also discussed. All of this with the aim to provide to readers a guide about recent advanced silver nanomaterials, used as colorimetric sensors in water.
\end{abstract}

Keywords: silver nanoparticles; colorimetric sensors; engineered nanomaterials; heavy metals detection; pesticides detection; water pollutants; water treatments; water monitoring

\section{Introduction}

In the last ten years nanotechnology has enabled the enhancement of low dimensional materials properties proponing their use in several application fields, such as sensors [1-12], optics [13-22], energy [23-26], catalysis [27,28] and biotechnology [29-34]. Among others the noble metal nanomaterials were developed by bottom up approach with various morphologies such as spheres, cubes, stars, flowers and wires, showing significant chemical-physical properties that allow to unique interactions with the environment [35-42]. Researchers are amazed by the possibility to produce gold and silver nanoparticles with specific morphology and surface functionalization, leading to new properties [43-45]. Moreover, advanced characterization methods allow one to study their capability to respond to changes in $\mathrm{pH}$, redox potentials, temperature, light and magnetic fields [46-51].

This represents a remarkable opportunity for their use in environmental monitoring applications, especially for silver nanoparticles (AgNPs), that are very easy to prepare, versatile and cheap materials [52,53]. Moreover, advances in the ligand chemistry of metal nanoparticles has opened up new opportunities to fabricate colorimetric sensors to assay various chemical and biomolecular species with good selectivity and sensitivity, which can thus be identified by visual readouts [54-56]. The colorimetric sensing applications of noble metal nanoparticles rely on a quantitative coupling between metal nanoparticles, resulting a dramatic change in the photonic properties via aggregation 
mechanisms, which leads changes in color from yellow to red in the case of AgNPs. For these reasons, the AgNPs have been considered promising visual readout sensors for the identification of various target analytes [57,58]. Importantly, AgNPs exhibit very high extinction coefficients, and the plasmonic band of AgNPs can be changed based on the size and distance, which makes them promising naked eye-distinguishable readout sensors $[55,59]$. In recent years, attention has also been paid to the environmental impact of engineered nanomaterials (ENMs) and several studies have been devoted to examine the toxicity of AgNPs in aqueous environments [60,61]. The toxicity mechanisms are still a subject of debate, but the size and coating surface appear to be the main toxicity factors $[62,63]$. The literature suggests that the toxicity of AgNPs is partially related to their dissolution and release of $\mathrm{Ag}^{+}$ions, although it is difficult to estimate the relative contributions of these phenomena. The toxicity also varies depending on the exposure concentrations and the maximum toxicity levels vary greatly from one taxon to another and are highly dependent on the overall biological community present in the environment [64-66].

In this broad ENMs scenario, this review tries to provide an up-to-date overview on silver nanoparticle-based materials, their synthesis, paying special attention to the stabilizers and most used ligands, characterization, properties and applications as colorimetric sensors for water pollutants.

There has been an explosion of scientific interest in AgNPs for sensing, as evidenced by the exponential growth in peer reviewed journal publications as shown in Figure 1a,b. Figure 1a depicts the number of peer reviewed journal articles published each year found using the keyword "silver nanoparticles as colorimetric sensor" as listed on Scopus over the last 10 years (2009-2019). Moreover, the interdisciplinarity of this research field is clearly highlighted (Figure 1b).
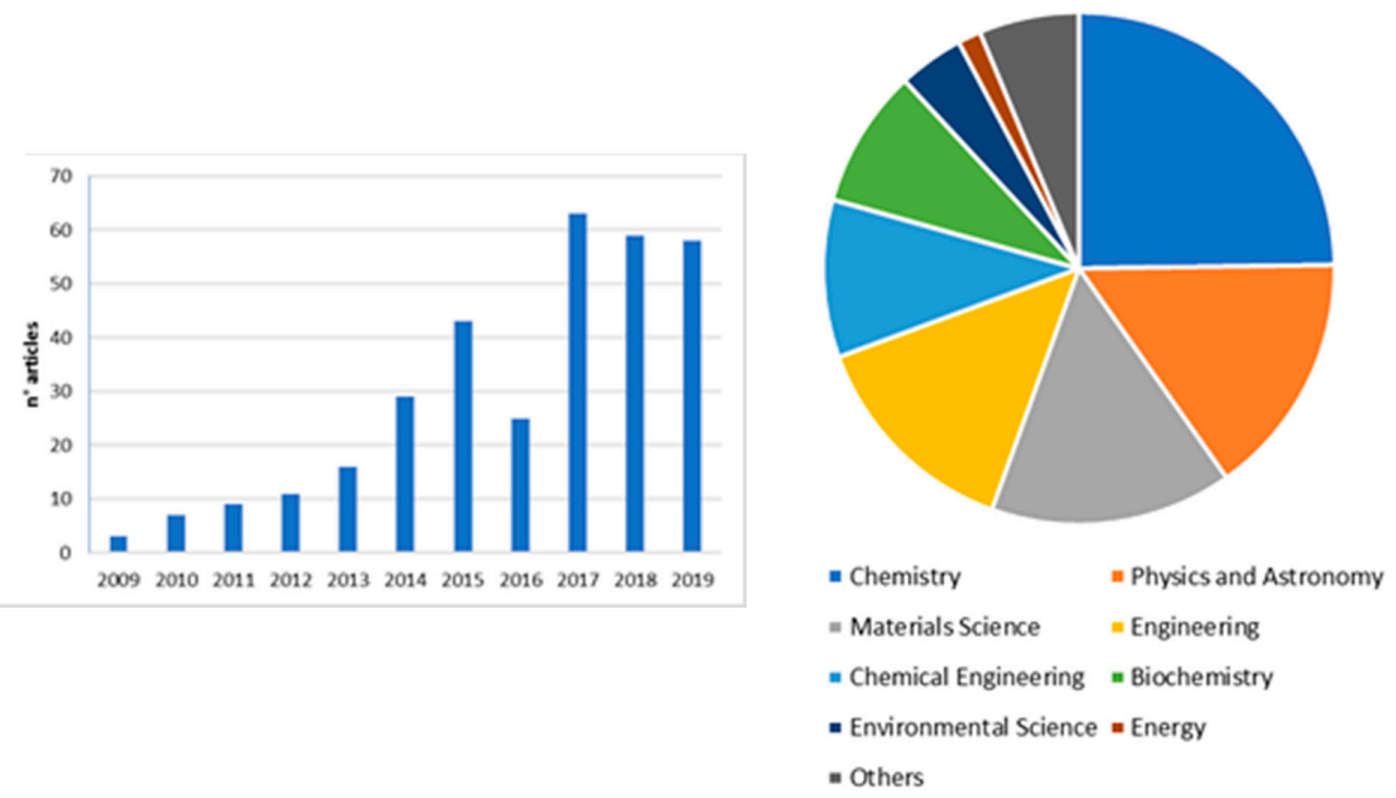

(a)

(b)

Figure 1. Data from Scopus.com in the last 10 years (2009-2019) for the keywords "silver nanoparticles as colorimetric sensors": (a) Number of publications per year; (b) Subjects areas involved in this research field.

The authors' choice was not to treat the aspects and applications of silver particles concerning their antibacterial properties, but rather the synthesis, characterization and main optical properties in the visible range of silver nanoparticles suitable for water pollutant monitoring and treatment, are presented, as schematized in Figure 2. The advantages and strategies of the recent silver-based materials, used for heavy metal and pesticides detection and water treatments, are examined, taking 
into account their dimensions, functionalization, selectivity and low detection limits (LODs). In fact, it is often enough to vary just a few experimental parameters to obtain systems with different selectivity and sensitivity. This is also demonstrated by the different reviews that have appeared in recent years and that often discuss how the same analyte can be simply monitored with systems based on different silver nanoparticles. All this, if on one side is an advantage, linked to the high versatility of the chemical synthesis, on the other it can be confusing. Starting from these assumptions, our work examines the recent literature on silver nanoparticles used as colorimetric detection materials for main water pollutants, to provide readers with a clear unique and updated guide.

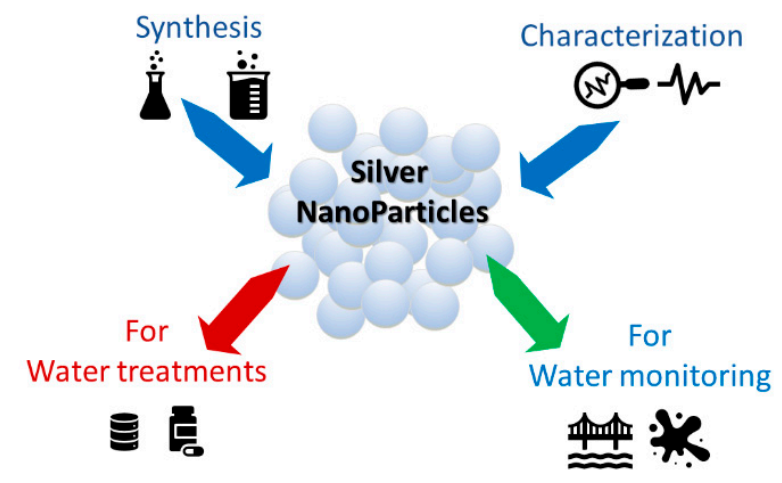

Figure 2. Main research fields on silver-based nanomaterials for water protection.

\section{Synthesis of AgNPs Used for Water Protection Applications}

The development of nanotechnology offers great opportunities to choose appropriate nanoparticle morphologies, sizes and functionalization, that allow one to improve the performance in a specific application field. For the sensor industry this is translated into the optimization of nanomaterial shape and functionalization, to improve sensor sensitivity, selectivity, reusability, ecosafety, and easy and cheap production [31,59,67-69]. The stake is the presence of different forms of functionalization on a single nanomaterial, with reproducible morphology, size and functionalities, with the aim to obtain ENMs, i.e., a single entity capable to carry out multiple actions. Many silver-based nanomaterials have been developed for environmental sensing applications, due their unique chemical-physical properties. In fact, they have easy modifiable morphology/size/surface, modulable optical absorption and scattering and wide surface area to volume ratio $(\mathrm{S} / \mathrm{V})$, suitable for an effective interaction with the environment. The surface properties of these materials are also the main component of their targeting characteristics: when the nanoparticles come into direct contact with surface of analyte, this can determine changes in some properties of the nanomaterial, such as in the local surface plasmon resonance (LSPR) and very often even in the color. LSPR is due to the interactions of electrons on the surface of noble metal nanoparticles with electromagnetic radiation: in this way silver nanoparticles produce strong extinction and scattering spectra, at around $400 \mathrm{~nm}$ in visible range of spectrum.

With regard to the functionalities it can be noted that acid and amino functionalities are often used also because they can facilitate the phenomena of aggregation/disaggregation when the $\mathrm{pH}$ of the tested solution changes. These phenomena can also be exploited to trap pollutants and remove them from water and later regenerate the original system by releasing pollutants in a controlled environment for displacement. The syntheses that use biomaterials or vegetal extracts as stabilizing and/or reducing agents deserve special mention. In this field, in the last ten years many new materials have been developed [55,70-72].

Many methods for synthesizing AgNPs by chemical, physical and biological processes, using both bottom up and top down approaches have been investigated [32,73-75]. A well-known chemical method for synthesizing AgNPs by a bottom up approach is wet reduction in the presence of capping agents. Capped AgNPs are prepared by using a water solution of silver nitrate as silver precursor, a ligand molecule and a suitable reducing agent such as sodium borohydride. 
Many approaches are used to functionalize the metal surface, as schematized in Figure 3a: (a) the ligand exchange strategy; (b) stabilization during the synthesis with a ligand with sulfur or nitrogen; (c) stabilization during the synthesis with two or more ligands; (d) stabilization during the synthesis with ligands with more functional groups [35,47,76-78]. The first approach, ligand exchange, is the simplest and most economic way to functionalize the silver surface. On the other hand, this functionalization method often displays poor control and reproducibility, because it is based on an equilibrium reaction associated with the Nernst distribution and depends on several parameters, such as the repeated exchange reactions with a large ligand excess, the diameter of the silver nanoparticles, and ligand steric hindrance. The presence of ligands during the synthesis allows for strict control of the surface coverage and guarantees the reproducibility, even if sometimes at the expense of the yield. Moreover, the presence of more ligand or more functional groups can be useful for post-synthesis engineering strategies. Indeed, some functionalities remain towards the outside of the particle and have a great ability to create a network between particles and interact with the external environment. Commonly, hydrophilic functionalities such as acid, amine, ester, alcohol are mostly preferred (Figure 3b).

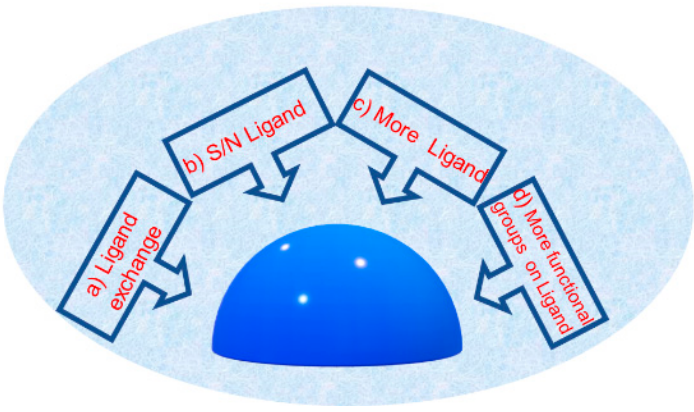

(a)

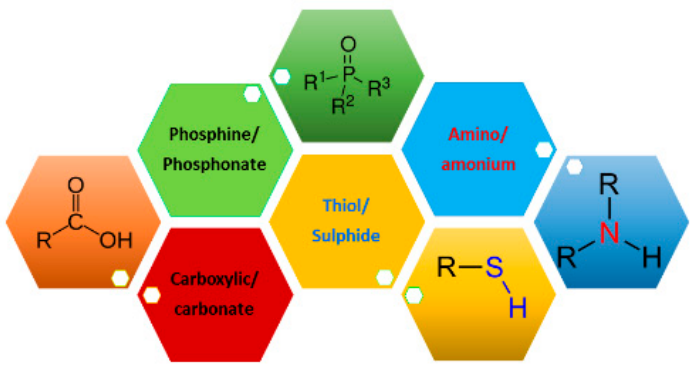

(b)

Figure 3. (a) Scheme of main methods for surface functionalization of silver surface; (b) main functional groups used for hydrophilic AgNPs.

The morphology plays a key role, especially for the possibility of having materials with different symmetries (spheres, AgNPs, cubes AgNCs) [79-87] or without defined and reproducible symmetry (stars, AgNSs, flower, AgNFs, wires, AgNWs) [69,88-94]. TEM images of silver nanoparticles of different geometries and shape are presented in Figure 4. The nanospheres, highly symmetrical particles, are the most studied because of their monodispersity and synthetic reproducibility, that assure the repeatability of experiments and results. Spherical AgNPs and their composites have a widely application range, mostly in biotechnology and sensors [79-81,85,95,96]. The AgNPs show a typical localized surface plasmon resonance (LSPR) whereby the electrons on the AgNPs surface interact with electromagnetic radiation, generating LSPR and producing extinction and scattering spectra, with absorption bands in the 370-470 $\mathrm{nm}$ range. Moreover, the opportune choice of surface functionalization and the presence of chemical or biological analytes can stimulate the aggregation-disaggregation phenomena, associated with LSPR band changes. Also, hollow spherical silver nanoparticles have an important role in biotechnological applications due to their role as fillers or rheological modifiers and easy synthesis [97]. In fact, the void space in hollow structures can be efficaciously used to capture specific molecules, and so their impact can be assessed in terms of density, volume fraction and dimension. On the other hand, the void area has been used to tune the refractive index, increase the active region for catalysis, and advance the ability to tolerate cyclic volume modifications. 


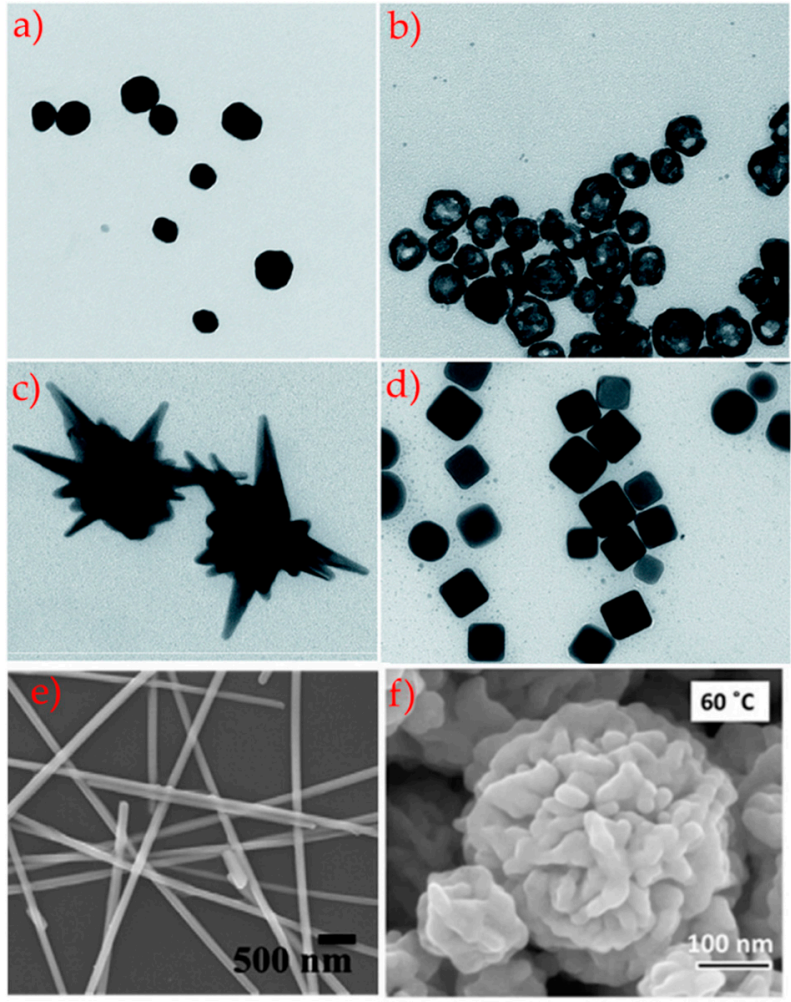

Figure 4. TEM images of AgNPs TEM micrographs presenting AgNPs with different geometry and shapes: (a) spherical silver nanoparticles, (b) hollow spherical silver nanoparticles, (c) nanostars, (d) cubic silver nanoparticles, adapted from [97]; (e) silver nanorods adapted from [98] and (f) silver nanoflower adapted from [69].

AgNCs have great anisotropy, improving signals based on the local field enhancement at the tips and corners. Despite many efforts in the design of new AgNCs, fine regulation is still necessary regarding their monodispersity and synthesis reproducibility as variations of the experimental parameters, such as the precursor concentrations, mixing conditions, temperature and reaction time, can lead to different results (see Table 1 ).

The AgNSs can be synthetized by two main procedures, namely seed-mediated and one-pot methods: the first way is the most used and involves the cetyltrimethyl ammonium bromide (CTAB) and polyvinylpyrrolidone (PVP), the second way uses zwitterionic surfactants, easier to remove than CTAB. The AgNSs have SPR tunability from 600 to 950 nm, like AgNFs.

The silver nanowires have anisotropic shape, inducing two plasmon bands: a transverse plasmon band, corresponding to an electron oscillation along the short axis of the rod, and a longitudinal plasmon band. This allows them to cover a vast spectroscopic range and is widely used in biotechnology.

The stability of the nanoparticles is highly influenced by their morphology, but above all by their functionalization. It is also good to clarify the concept of stability. The term "nanoparticle stability" is widely used to describe the preservation of a particular nanostructure property ranging from aggregation, composition, crystallinity, shape, size, and surface chemistry. As a result, this catch-all term has various meanings, which depend on the specific nanoparticle property of interest and/or application. Many and different functionalizations can be introduced on surface of the silver nanomaterials, inducing stability or not. The most used functionalizations can be amines, thiols, sulfonates, alcohols, esters, and acids. In Table 1 common functionalities usually used for several morphologies are reported, highlighting the importance of surface chemistry in silver nanomaterials for environmental and water protection. 
Table 1. Main morphologies reported with dimension and surface functionalities.

\begin{tabular}{|c|c|c|c|c|}
\hline Morphology & Size $(\mathrm{nm})$ & Functionality & Detected Analyte & Ref. \\
\hline \multicolumn{5}{|l|}{ Nanospheres } \\
\hline & - & Citrate/ascorbic acid & Hg (II) & [95] \\
\hline & $5-8$ & Sodium 3-mercapto-1-propanesulfonate & Co (II) Ni (II) & [96] \\
\hline & 25 & Polyvinyl alcohol/dithizone & $\mathrm{Pb}(\mathrm{II})$ & [80] \\
\hline & $5-8$ & Citrate/L-cysteine & $\mathrm{Hg}$ (II) & [79] \\
\hline & 70 & $\mathrm{HO}-\mathrm{NH}_{2} \cdot \mathrm{HCl}$ & Malachite green & [81] \\
\hline & 50-200 & Ascorbic acid & Hg (II), $\mathrm{S}^{2-}$ & [85] \\
\hline & 20 & Riboflavin & $\mathrm{Cu}(\mathrm{II})$ & [99] \\
\hline & $8-10$ & L-Tyrosine & Mn (II) & [70] \\
\hline & $5-20$ & Carrageenan & $\mathrm{Cu}(\mathrm{II}), \mathrm{S}^{2-}$ & [83] \\
\hline & $5-17$ & Mercaptosuccinic acid & As (III) & [100] \\
\hline & 8 & Citrate & $\mathrm{Hg}$ (II) & [101] \\
\hline \multicolumn{5}{|l|}{ Nanocubes } \\
\hline & 56 & Alginate & $\mathrm{Hg}(\mathrm{II})$ & [44] \\
\hline & 50 & Poly(vinyl pyrrolidone) & Cysteine & [45] \\
\hline & 45 & Poly(vinyl pyrrolidone) & Hydrogen peroxide, hydrazine & [53] \\
\hline & 150 & Poly(vinyl pyrrolidone) & $\mathrm{H}_{2} \mathrm{O}_{2}, \mathrm{H}_{2} \mathrm{~N}_{2}$ & [53] \\
\hline & 200 & Poly(vinyl pyrrolidone & $\mathrm{H}_{2} \mathrm{O}_{2}$ & [84] \\
\hline \multicolumn{5}{|l|}{ Nanostars } \\
\hline & $200-250$ & Hydroxylamine & Pesticides & [89] \\
\hline & $250-400$ & Citrate & R6G & [102] \\
\hline & 100 & Lauryl sulfobetaine & Melamine & [88] \\
\hline \multicolumn{5}{|l|}{ Nanoflowers } \\
\hline & 10 & Hexamethylenetetramine & NO & [90] \\
\hline & 200 & Sodium citrate & Permethrin & [91] \\
\hline & 110 & Sodium dodecyl sulphate & Polychlorinated biphenyls & [92] \\
\hline \multicolumn{5}{|l|}{ Nanowires } \\
\hline & $50-100$ & Graphene oxide & Glucose & [93] \\
\hline & $10-300$ & $\mathrm{Fe}_{3} \mathrm{O}_{4}-\mathrm{MS}$ & Humidity & [94] \\
\hline
\end{tabular}

In many of the examples listed in Table 1, the functionalization plays a key role in that it guides the aggregation/disaggregation mechanisms of AgNPs in the presence of specific analytes. The interaction between the functional groups exposed to the outside of the AgNPs can allow their approach to the analyte which, coordinating with several AgNPs, actually brings them together and aggregates them, or simply the surface functionalization induced by the ligand stabilizes the surface of the particles only in some areas, leaving others uncovered, ready to interact with analytes and, again, favoring the aggregation of AgNPs. These aggregation/disaggregation mechanisms cause alterations of the SPR band, both in terms of intensity and $\lambda_{\max }$. From the variations of the SPR it is possible to trace the concentration of the analyte. The color change of the system, as well as the red shift/blue shift of the SPR peak, are typical features of these mechanisms. The disaggregation effect of the analyte can also be used for analyte detection and, in this case, the absorbance ratio between two specific shoulders is used for measurable calibration purposes. It is important to note that in some cases the change in color is due to a shape change and not at an aggregation mechanism. The advantages of this "colorimetric approach" are many, i.e., simplicity, low cost, portability, and they will be specifically addressed in the next paragraphs.

\section{Optical Sensing Properties}

Micro- and nanomaterials, such as metal nanoparticles, are characterized by different chemical and physical properties with respect to the same bulk material. These characteristics are related to the surface area to volume ratio $(\mathrm{S} / \mathrm{V})$. Bulk materials are characterized by a low $\mathrm{S} / \mathrm{V}$ ratio, since the surface atoms are only $\mathrm{z}$ few in number compared to the entire number of atoms present in the volume. In this case, the surface contribution can be considered negligible. By decreasing the size of the materials the value $\mathrm{S} / \mathrm{V}$ increases and the contribution of the surface becomes more and more important than the volume one. Thus, in micro- or nanomaterials the surface atoms or molecules play a fundamental role and the properties are mainly affected by surface moieties. Among the many chemical and physical features, 
the optical ones are very interesting, and they are often exploited for the fast measuring techniques and the easy interpretation of the data. When the light interacts with a micro/nano system many processes occur, such us reflection, transmission, light scattering, absorption and fluorescence. One or more of these properties can therefore be exploited not only for the bare characterization of the samples, but also for practical applications in many fields of science, engineering or in industrial processes. For example, silver nanoparticles are characterized by specific absorption or fluorescence bands with characteristic intensity, maximum and full width at half maximum (FWHM), but when the system is altered by means of a change of the external medium or by the introduction of contaminants, the features of the bands are modified. This type of sensitivity to the external environment could be used in the field of optical sensing to monitor the presence of pollutants. For example, those based on colloidal solutions of metal nanoparticles. In this case, when a light beam impinges on the colloidal solution the phenomenon of localized surface plasmon resonance (LSPR) occurs. A plasmon is a collective oscillation of the free electrons in a noble metal. These plasmon oscillations can be considered as mechanical ones for the electron gas of a metal and the presence of an external electric field causes displacements of the electron gas with respect to the fixed ionic cores. For bulk plasmons, these oscillations occur at the plasma frequency and have a certain energy:

$$
E_{p}=\hbar \sqrt{\frac{n e^{2}}{m \varepsilon_{0}}}
$$

where $\varepsilon_{0}$ is the permittivity of free space, $n$ is the electron density, $e$ is the electron charge and $m$ is the electron mass [103]. At the surface of a bulk metal, the surface plasmons are optically excited, and light can be coupled into standing or propagating surface plasmon modes through a grating or a defect in the metal surface. Because it is the oscillating electric field of the incoming plane wave that excites surface plasmons, light with a high angle of incidence (that is, with wave vector k nearly parallel to the surface) couples most efficiently. When a surface plasmon is confined to a particle of a size comparable to the wavelength of light, that is, a nanoparticle, the particle's free electrons participate in the collective oscillation, and it is termed a localized surface plasmon (LSP). The LSP has two important effects: first, electric fields near the particle surface are greatly enhanced, this enhancement being greatest at the surface and rapidly falling off with distance and second, the particle optical extinction has a maximum at the plasmon resonant frequency, which occurs at visible wavelengths for noble metal nanoparticles. To understand in depth how this localized surface plasmon resonance (LSPR) arises, we must turn to scattering theory [104].

The first description of optical behavior is due to Gustav Mie in the early 20th century, that developed an analytical solution to Maxwell's equations that describes the scattering and absorption of light by spherical particles with small dimension $(d \ll \lambda)$. Mie's approach depends mainly on the size of nanoparticles (about $10 \mathrm{~nm}$ ), refractive index of medium where the MNPs are dispersed and is strictly applicable only to spherical particles [105]. A step forward has been made by Gans who generalized Mie's result to spheroidal particles of any aspect ratio in the small particle approximation. Here, the anisotropic behavior due to the spheroidal shape is taken in account, to predict the optical properties of MNPs [106]. For different shapes than the previous ones, it is possible to obtain the optical behavior only in numerical ways, using various approximations such as finite difference time domain (FDTD), discrete dipole approximation (DDA), and finite element method (FEM) [107]. Summarizing, absorption spectrum of MNPs depends on the type of metal, shape, dimension and the refractive index of the medium [108]. Figure 5A shows the change of color of silver colloidal solution depending on size and shape of silver nanoparticles and Figure 5B the related optical absorption spectra [109]. In Figure 5C the morphological aspects of the silver nanoparticles obtained by TEM characterization are reported together with fluorescence microscope images of the nanosystems. 


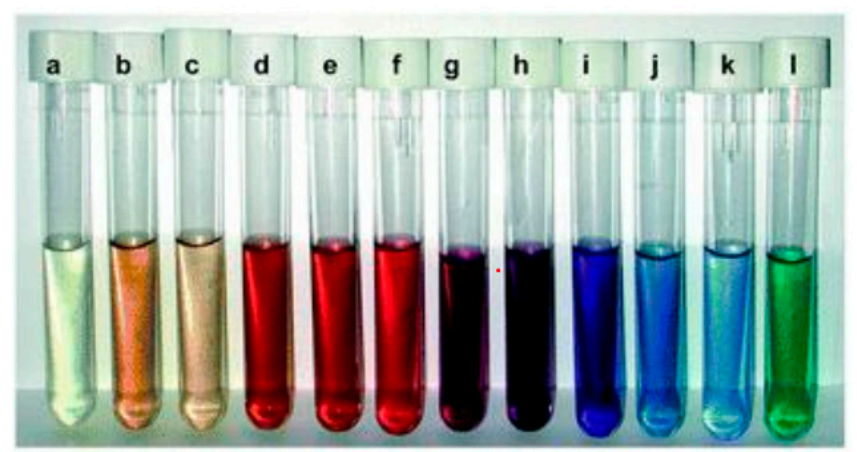

(A)

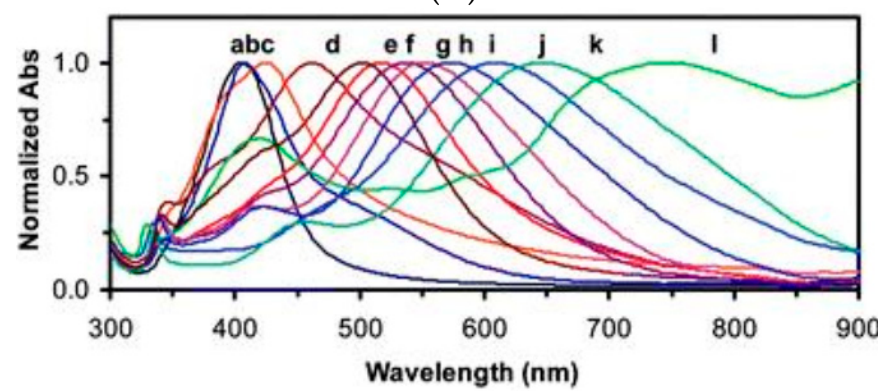

(B)
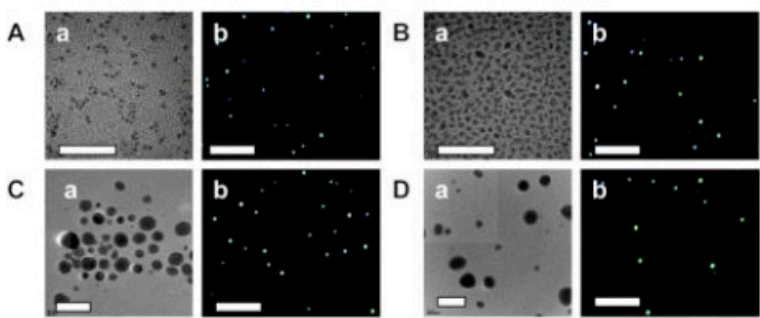

E
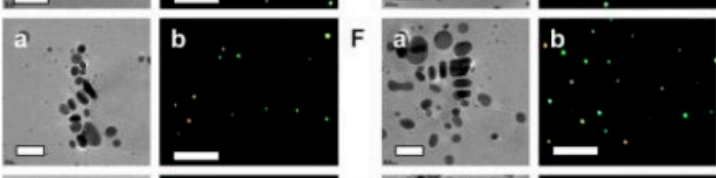

G
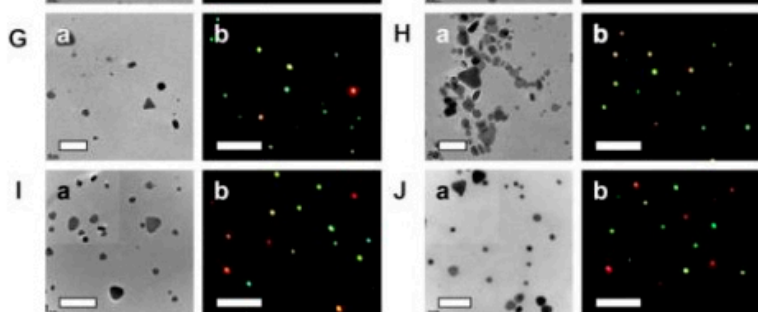

K
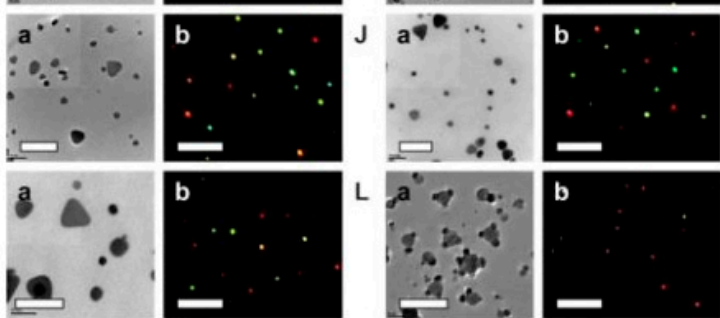

b
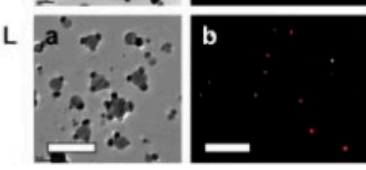

(C)

Figure 5. The change of color of colloidal solution depending on size and shape of silver nanoparticles in (A) and related optical absorption spectra (B); (C) The Figures (A-L) show the TEM images (a) related to the different shapes of Ag nanosystems and the NPs imaged under optical diffraction limit (b). The scale bars in (a) are 40 and $100 \mathrm{~nm}$ for (A-H) and (I-L), and $10 \mu \mathrm{m}$ in (b), respectively. The scale bars in (b) represent the distances among NPs, but not the sizes of NPs [109].

The plasmonic band can be used as a useful tool for an optical sensor. Monitoring the peak position, the FWHM and the relative shape, it is possible to reveal the presence of specific analytes. The changes of these features are connected to the mechanisms of interaction between the MNPs 
and the contaminants and depend on case by case. Some general aspects are reported in this section. In several cases, we observe a shift of the LSPR band to lower energy with a broadening at the same time and sometimes, also a color change of colloidal solution can be appreciated. Indeed, the electrostatic stabilization of MNPs guaranteed by capping agents is eliminated by the presence of the contaminant, that interacts with the ends of the capping agents $[110,111]$. When MNPs interact with contaminants the particles can form aggregates having various sizes, thus a multi-dimensional dispersion is obtained and consequently the LSPR band will experience broadening. Some optical detectors are just based on this mechanism. A representative scheme of this type of process is shown in Figure 6, where the optical behavior as function of $\mathrm{Ni}$ (II) content (a) is presented together with TEM images of silver nanoparticles in absence (b) and in presence (c) of 1.0 ppm Ni(II) contaminant [112].

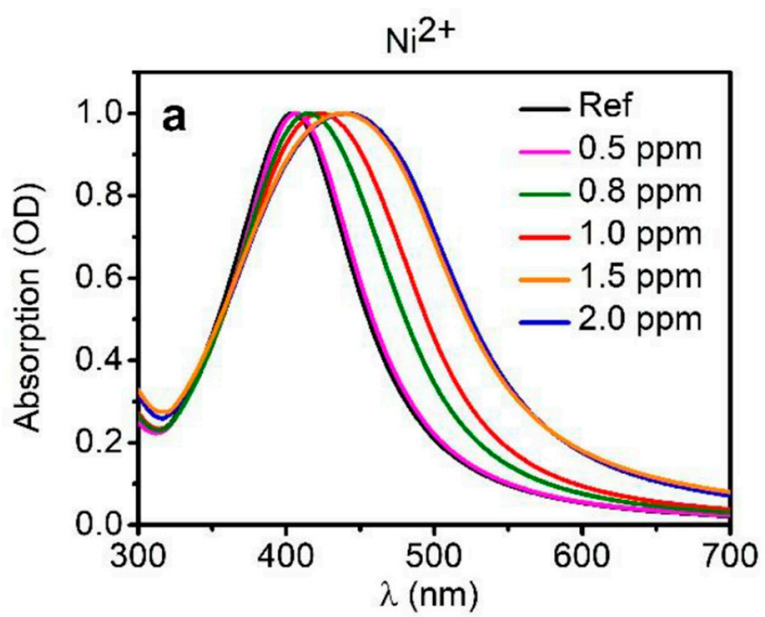

(a)

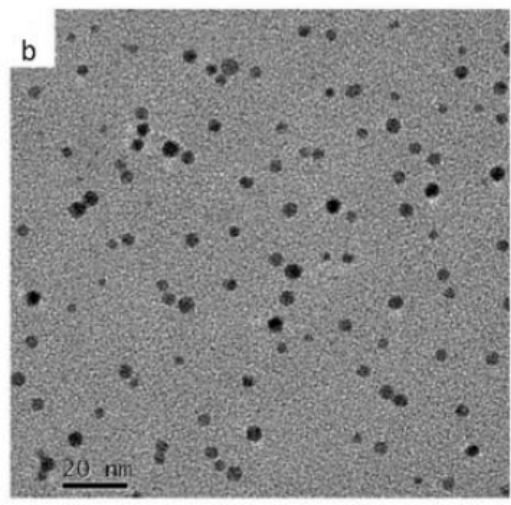

(b)

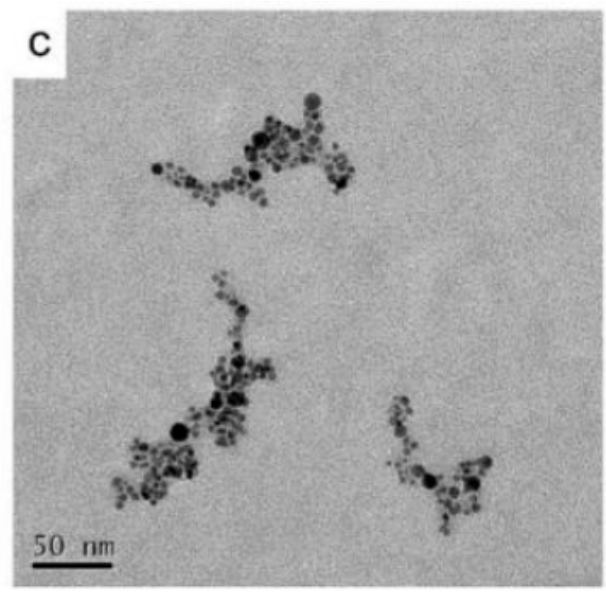

(c)

Figure 6. (a) Optical behaviour of AgNPs colloidal solution without (black line) and with different $\mathrm{Ni}(\mathrm{II})$ contaminations (colored lines); TEM images of (b) AgNPs and (c) the system contaminated by $\mathrm{Ni}(\mathrm{II})$ [112].

In other cases, the optical behavior is the opposite, thus the LSPR band suffers a shift to the shorter wavelengths or in some cases, there is also a decrease of the band intensity. Several cases where this phenomenon occurs are reported in the literature [113-115]. The reasons for this blue shift depend on the chemical structure of the sensor and on the type of analyte. For example, in the field of heavy metal ions monitoring, the case of $\mathrm{Hg}$ (II) contamination is representative of this behavior. Indeed, $\mathrm{Hg}$ (II) ions can interact with the surface of silver nanoparticles with the help of thiol capping agents, modifying the shape of the particles as reported by Chen et al. [116] and shown in Figure 7a: The label 1 represents the colloidal solution of silver nanoprisms, 2 the system with $700 \mathrm{nM} \mathrm{Hg}$ (II) and 3 the system 
with a $1500 \mathrm{nM}$ concentration of $\mathrm{Hg}$ (II). In Figure $7 \mathrm{~b}$ the change of the curve shape in the presence of $\mathrm{Hg}$ (II) are shown.

(A)

(B)
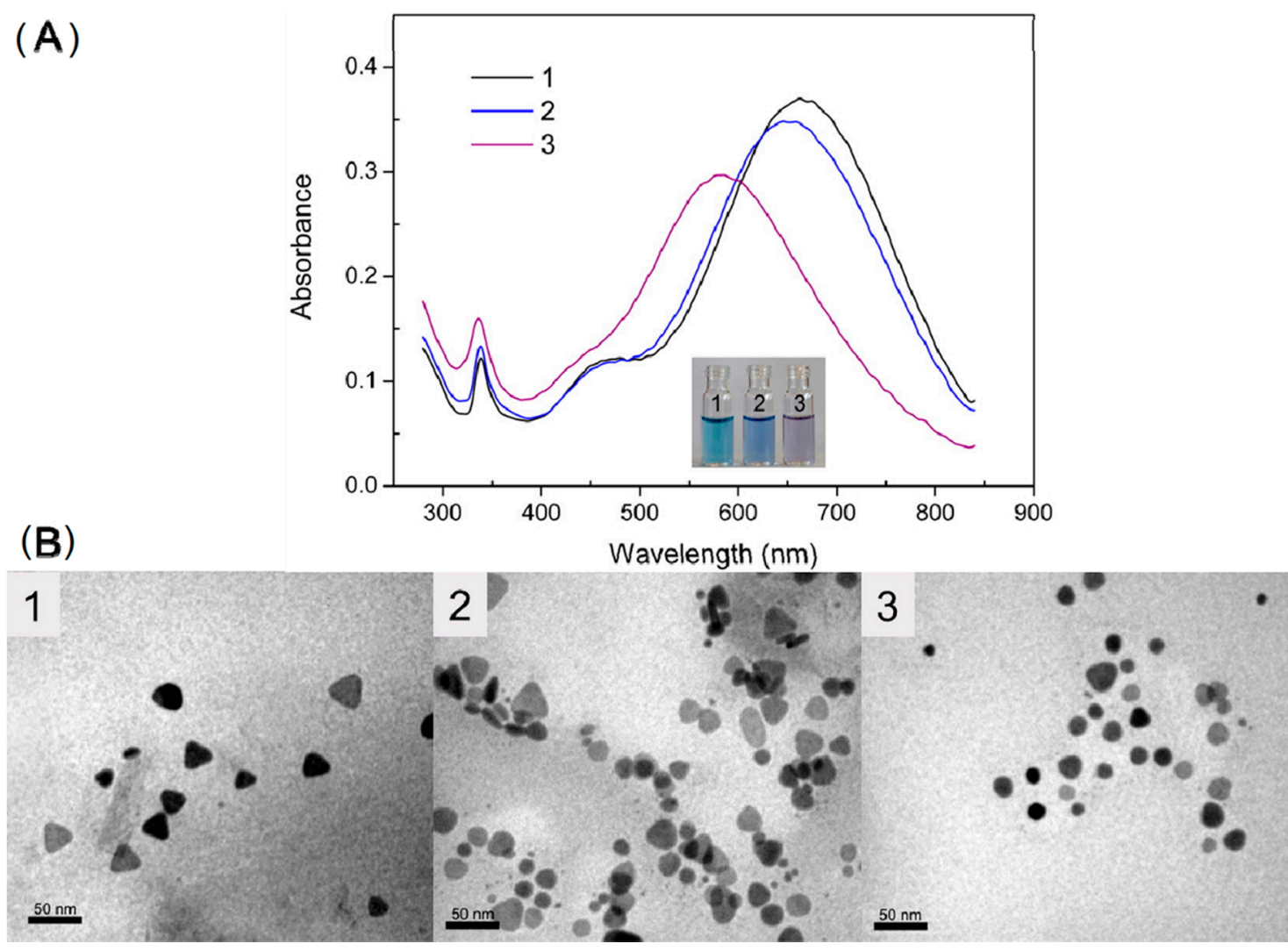

Figure 7. (A) UV-Vis spectra of (1) silver nanoprisms, (2) with $700 \mathrm{nM}$ of $\mathrm{Hg}$ (II) and (3) with $1500 \mathrm{nM}$ of $\mathrm{Hg}$ (II). (B) TEM images of (1) AgNPs, (2) with $700 \mathrm{nM}$ of $\mathrm{Hg}$ (II) and (3) with $1500 \mathrm{nM}$ of $\mathrm{Hg}$ (II) [116].

In other cases, the $\mathrm{Hg}$ (II) ions produce the formation of a nano-alloy, due to a redox reaction involving $\mathrm{Ag}(0)$ and $\mathrm{Hg}$ (II) which modifies the plasmonic properties and as a consequence the optical absorption features [117-119].

\section{Main Water Pollutants Detected by AgNPs}

Environmental protection and monitoring of water quality are important issues since water contamination represents a high human health risk. Many recent studies have reported a possible use of metal nanoparticles in liquid solutions as optical sensors for water contaminants such as heavy metal ions and pesticides [120,121]. In this paragraph we report some of these studies, even if their amount is so large that is difficult to provide a complete and exhaustive overview.

Determination of specific water contaminants can be performed in many ways such as inductively coupled plasma mass spectrometry (ICP-MS), high performance liquid chromatography (HPLC), atomic fluorescence spectroscopy (AFS), flame atomic absorption spectroscopy (FAAS), etc. However, the most of them involve time consuming preparation of the samples, sophisticated and expensive instruments and highly trained personnel to perform the measurements. All these drawbacks have pushed the research in recent years towards innovative sensors based on simple and cost effective procedures. In this framework, colorimetric sensors of water pollutants are one of the best choices since the necessary equipment to estimate the contaminant concentration is very simple and economic and in addition, such sensors for the determination of contaminants are usually fast and allow on-site detection since they do not require heavy, bulky and sophisticated instruments. Many colorimetric sensors based on silver nanoparticles have been studied and developed in the last years. The main 
differences are related to the stabilizing agents employed. Such capping agents increase the protection of the nanoparticle core and at the same time give to the NPs the suitable functionalization to interact selectively with specific water contaminants.

In general, the working principle of silver NPs colorimetric optical sensors is based on a change of the optical absorption when they are in contact with specific analytes. The gradual change of the optical property as a function of the contaminant amount can be exploited to synthesize an effective optical sensor. The sensitivity of these type of optical sensors relies on the type of functional moiety responsible for bringing change in the vicinity of silver NPs, which as a consequence changes the observed SPR intensity, energy and band shape, enabling adequate quantification of target molecules.

\subsection{Mercury}

Several heavy metal ions are highly dangerous for the environment and human beings. One of the most lethal is $\mathrm{Hg}$ and many recent works have been published in this field. One example is an ultra-sensitive colorimetric detection of $\mathrm{Hg}$ (II) based on silver nanoparticles functionalized with mercaptobenzo heterocyclic compounds (mercaptobenzooxazole (MBO), mercaptobenzoimidazole (MBI) and mercaptobenzothiazole (MBT)) that has been recently reported [122]. The authors suggest that the sensor mechanism of these systems is based on a redox reaction involving $\mathrm{Ag}(0)$ and $\mathrm{Hg}$ (II) that leads to the formation of $\mathrm{Ag}-\mathrm{Hg}$ nanoalloys and consequent color changes of the solution which confirms the presence of $\mathrm{Hg}(\mathrm{II})$ in water. These nanoparticles present a LOD of $1.8 \mathrm{ppt}(9.2 \mathrm{pM}), 9.2 \mathrm{ppt}$ (46 pM) and 18.4 ppt (92 pM) for MBO, MBI and MBT, respectively.

An interesting and rapid colorimetric sensing method for the detection of $\mathrm{Hg}$ (II) was developed based on the morphology transition of $\mathrm{Ag}$ nanoprisms at room temperature. In particular, the presence of $\mathrm{Hg}$ (II) induces a deprotection and a change of the morphology of 1-dodecanethiol $\left(\mathrm{C}_{12} \mathrm{H}_{25} \mathrm{SH}\right)$-capped silver nanoprisms. During the interaction process, the silver atoms are consumed producing a change in the particle morphology that results in a change of the color and UV-Vis absorption spectra of the colloidal solution. This sensor shows a good selectivity for $\mathrm{Hg}$ (II) in the concentration range 10-500 nM, the surface plasma resonance spectral band of the silver nanoprisms emerged as a blue shift and exhibited a good linear relationship, and the limit of detection was $3.3 \mathrm{nM}$ [116].

In some cases, another optical property, namely fluorescence, can also be exploited for sensing applications. An example is the case of a $\mathrm{Hg}$ (II) sensor for neutral water that has been developed using riboflavin-stabilized Ag nanoparticles via a turn off-turn on mechanism [123]. The working principles of this system can be summarized as follows: Upon the formation of riboflavin-stabilized AgNPs the color of the solution becomes deep orange, but on addition of trace amounts of $\mathrm{Hg}$ (II) the color reverts back to yellow. The photoluminescence property of riboflavin is quenched by the formation of Ag nanoparticles but on addition of low concentrations of $\mathrm{Hg}$ (II) the PL intensity of the solution is enhanced up to nine times. Both the color and photoluminescence properties of the riboflavin solution are used as sensitizing tools showing a sensitivity up to $5 \mathrm{nM} \mathrm{Hg}$ (II) concentration, the sensor is quite fast (sensing time is around one minute) and selective between 11 ions and the color change can be easily appreciated, even by the naked eye.

Another example is fluorescein-functionalized AgNPs that have been synthesized as colorimetric probes for the detection of mercury ions by 1D-chain formation. Changes in the SPR bands as well as colors due to the network of 1D assemblies of NPs were observed. The chelation interaction of the $\mathrm{Hg}$ (II) ions with the carboxylate groups on the surface of the systems is responsible for the selective formation of chains between the NPs modulated for the $\mathrm{Hg}$ (II) metal ions [124].

Other systems based on different functionalizations of silver nanoparticles for $\mathrm{Hg}$ (II) ion detection have been developed in the last years. To cite only some of them: 2-aminopyrimidine-4,6-diol [115], bifunctionalized with citrate and L-cysteine [79], starch-coated NPs in presence of $\mathrm{HNO}_{3}$ [125], gelatin funcionalized [126] and leaf extract of Dahlia pinnata [71]. 


\subsection{Nickel}

A similar mechanism to the one presented in [116] for $\mathrm{Hg}$ (II), has been used also for $\mathrm{Ni}$ (II) detection. In this case, triangular silver nanoprisms were synthesized by a modified seed-mediated growth method, and upon addition of $\mathrm{Ni}$ (II) ions these triangular nanostructures showed a significant colorimetric change from blue to yellow as a function of the $\mathrm{Ni}$ (II) ion concentration. $\mathrm{Ni}$ (II) ions serve as a catalyst for the generation of $\mathrm{H}_{2} \mathrm{O}_{2}$ in a citrate-capped triangular silver nanoprisms colloidal solution. The oxidative etching with $\mathrm{H}_{2} \mathrm{O}_{2}$ formed in the colloidal solution sculptured the sharp corners/edges of the prisms to produce circular Ag nanodisk. The sensor showed a high linearity for $\mathrm{Ni}$ (II) concentration in the range of 0 to $30 \mu \mathrm{M}$ with a limit of detection of $21.6 \mathrm{nM}$ in aqueous solution [127]. The color change of the solution in presence of different amount of $\mathrm{Ni}$ (II) is impressive as shown in Figure 8A. The sensing mechanism is shown in Figure 8D: the triangular Ag nanoprism colloidal solution including $\mathrm{O}_{2}$ and $\mathrm{H}_{2} \mathrm{O}$ generates $\mathrm{H}_{2} \mathrm{O}_{2}$ upon addition of $\mathrm{Ni}$ (II). Oxidative etching of the sharp corners/edges of the triangular AgNPrs by $\mathrm{H}_{2} \mathrm{O}_{2}$ leads to the formation of Ag circular nanodiscs and occurs with a significant colorimetric change.

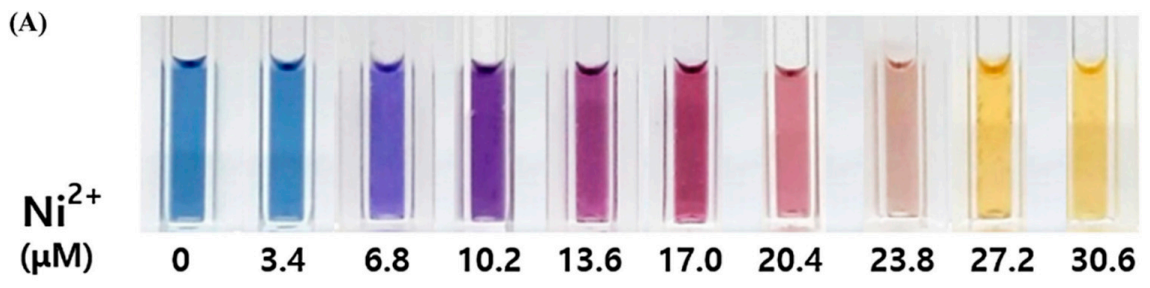

(B)

(C)

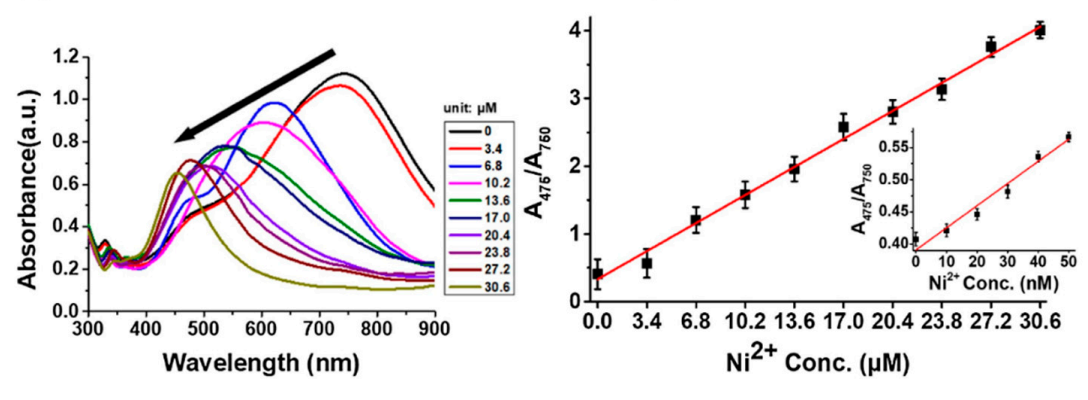

(D)
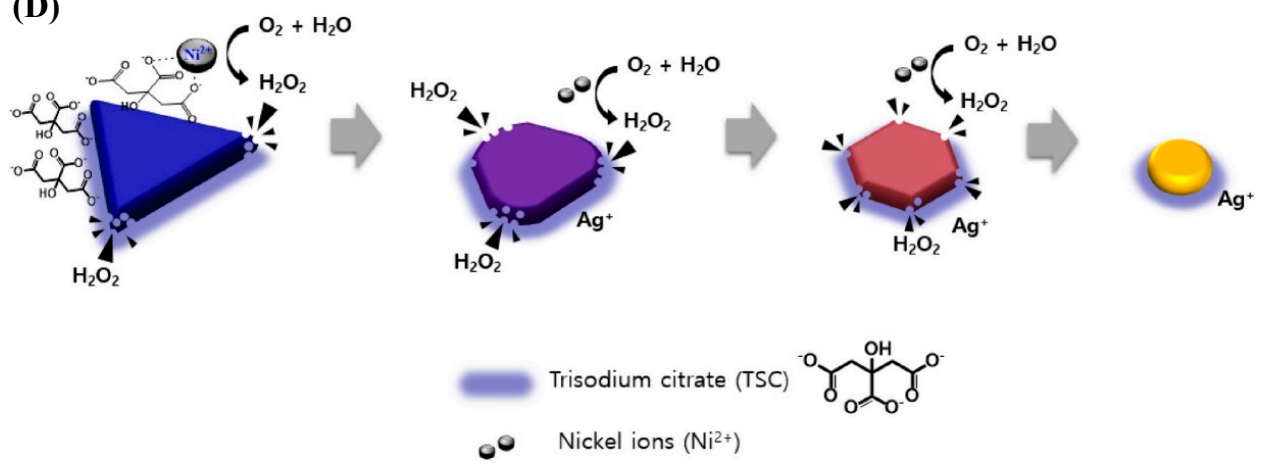

Figure 8. (A) Color change of the triangular silver nanoprisms upon addition of 10 different concentrations of $\mathrm{Ni}$ (II) $(0.0$ to $30.6 \mu \mathrm{M})$ at $\mathrm{pH} 8$ and $15{ }^{\circ} \mathrm{C}$; (B) UV-vis absorption spectra of the colloidal solutions as a function of $\mathrm{Ni}$ (II) concentration; (C) absorption ratios (A475/A750) from the UV-vis absorption spectra as a function of the Ni (II) ion concentration (0.0 to $30.6 \mu \mathrm{M})$. The inset shows the same absorption ratios but for lower concentrations of $\mathrm{Ni}$ (II); (D) The sensing mechanism of citrate-capped triangular AgNPrs for Ni(II) ions. (Reference. [127]). 
Other colorimetric sensors for $\mathrm{Ni}$ (II) are for example, the one based on glutathione-stabilized silver nanoparticles [128]. In this case, the synthesized nanoparticles are yellow in color due to the intense surface plasmon absorption band, while in the presence of Ni (II), the initial color turns to a deep orange accompanying the broadening and red shifting of SPR band. The selectivity of this system was tested with good result and the LOD was $7.5 \times 10^{-5} \mathrm{~mol} / \mathrm{L}$.

Another type of sensor is the one based on a dual-ligand strategy. In this case adenosine monophosphate and sodium dodecyl sulfonate were both used as ligands to modify AgNPs. The presence of $\mathrm{Ni}$ (II) induces the aggregation of the NPs through cooperative electrostatic interaction and metal-ligand interaction, resulting in a color change from bright yellow to orange. Such a sensor works in the concentration range of 4.0 to $60 \mu \mathrm{M}$ and has a detection limit of $0.60 \mu \mathrm{M}$ [129].

Also, functionalization of AgNPs with a hydrophilic thiol (3-mercapto-1-propanesulfonic acid sodium salt, 3MPS) was recently reported. The change of the SPR band in the UV-Vis range as a function of the $\mathrm{Ni}$ (II) concentration results in a color change of the solution. The working range was 0.1-1.0 ppm with a limit of detection of 0.3 ppm [96].

\subsection{Copper}

Copper is another dangerous ion that can contaminate water and functionalized silver NPs can effectively help in the detection of this contaminant. For example, recently the detection of $\mathrm{Cu}$ (II) ions based on coordination reactions of copper ions with casein peptide-functionalized silver nanoparticles has been reported. This system leads to a distinct color change of the solution from yellow to red. Such a system has a good detection limit of about $0.16 \mu \mathrm{M}$ with a high linearity in the $0.08-1.44 \mu \mathrm{M}$ concentration range [130].

A simple and green method for preparing uniform silver NPs exploiting self-polymerized 3,4-dihydroxy-L-phenylalanine as the reducing and stabilizing agent in aqueous media has been recently reported [131]. The functionalized silver NPs showed selectivity for $\mathrm{Pb}$ (II) and $\mathrm{Cu}$ (II) detection, as reported in Figure 9, with LOD for the two ions as low as $9.4 \times 10^{-5}$ and $8.1 \times 10^{-5} \mathrm{M}$, respectively. The sensing mechanism is based on the aggregation of functionalized AgNPs in presence of $\mathrm{Pb}$ (II) and $\mathrm{Cu}$ (II) as reported by the authors with TEM images. Therefore, the change in the solution color and the observed intensity ratio in Figure $9 \mathrm{C}$ are associated with the aggregation behavior of the AgNPs.

(A)

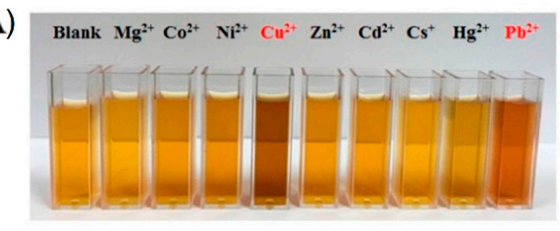

(B )

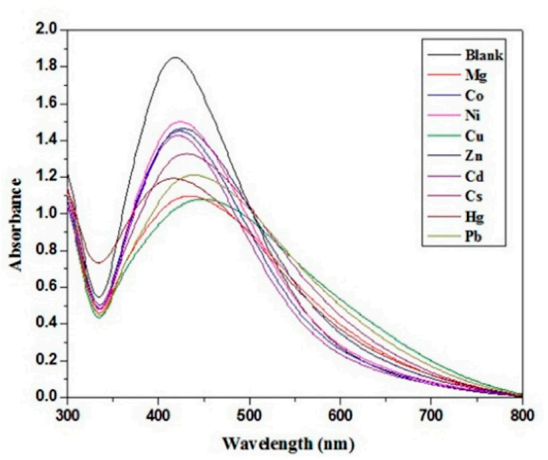

(C)

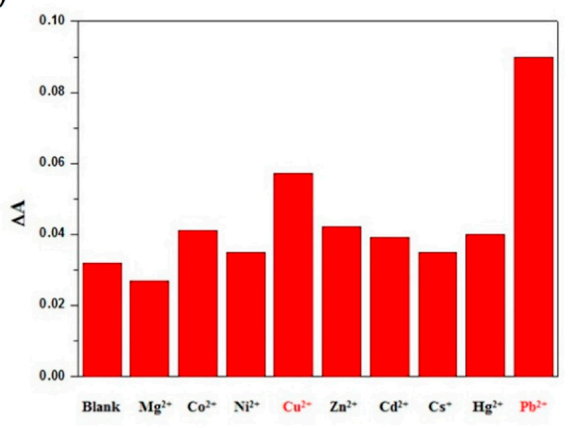

Figure 9. (A) solutions of polymerized 3,4-dihydroxy-L-phenylalanine silver NPs in presence of different metal ions with concentration of $0.1 \mu \mathrm{M}$ : in red the metal ions which induce color variation, i.e., $\mathrm{Cu}$ (II) and $\mathrm{Pb}$ (II); (B) UV-Vis absorption spectra of the colloidal solutions after mixing with $0.1 \mu \mathrm{M}$ metal ion; (C) absorption ratio of the solutions with various metal ions (Reference [131]). 
Another green synthesized $\mathrm{Cu}$ (II) colorimetric sensor based on riboflavin-stabilized silver nanoparticles is the one based on AgNPs prepared from Cucumis melo juice by a green chemistry approach [99]. The system showed an intense absorption band at $404 \mathrm{~nm}$ and its intensity depends on the presence of $\mathrm{Cu}$ (II) in solution. The selectivity for $\mathrm{Cu}$ (II) was excellent and a linear detection range from $5 \mathrm{nM}$ to $100 \mathrm{nM}$ with a detection limit of $1.12 \mathrm{nM}$ was found.

\subsection{Iron}

Silver NPs can also be used for colorimetric determination of Fe (III) ions as recently reported by some authors. The first example is based on chitosan-capped silver nanoparticles [113]. Such functionalized NPs exhibit a strong surface plasmon resonance band which disappears in the presence of increasing concentrations of Fe (III) ions. The system showed a visually detectable color change from brownish-yellow to colorless for the selective determination of Fe (III). The distinct color change can be detected by the naked eye. The method showed good selectivity for Fe (III) with the lowest detection concentration of $0.53 \mu \mathrm{m}$ and the system was successfully applied for the determination of Fe (III) in real samples.

Another example is based on N-acetyl-L-cysteine-stabilized AgNPs. The synthesized nanoparticles show a strong SPR around $400 \mathrm{~nm}$ and the intensity decreases with the increasing of $\mathrm{Fe}$ (III) concentration. Based on the linear relationship between SPR intensity and concentration of Fe(III) ions, such system can be used for the sensitive and selective detection of Fe (III) ions in water with a linear range from $80 \mathrm{nM}$ to $80 \mathrm{mM}$ and a detection limit of $80 \mathrm{nM}$ [132].

Moreover, starch-coated silver nanoparticles have a SPR band at $408 \mathrm{~nm}$, and are able to detect the presence of $\mathrm{Fe}$ (III) and discriminate it from Fe (II). This sensor has a very good sensitivity and a linear response over the range of $0.7-7 \mathrm{mg} / \mathrm{L}$. Furthermore, the detection limit of this smart sensing system is found to be $0.1 \mathrm{mg} / \mathrm{L}$ [133].

\subsection{Manganese}

Mn (II) is another environmentally toxic metal ions. Recently, a green method for the synthesis of L-tyrosine-stabilized silver NPs in aqueous medium under ambient sunlight irradiation was reported [70]. The synthesized Ag NPs are found to be highly sensitive to $\mathrm{Hg}$ (II) and Mn (II) ions with the detection limit for both ions as low as $16 \mathrm{nM}$. Another system is based on alginate-stabilized silver nanoparticles which act as a label-free colorimetric sensor for quantification of Mn (II) metal ions with excellent selectivity and sensitivity and detection in aqueous solution in the range of 1-10 $\mu \mathrm{M}$. In this case, the binding forces between functionalized AgNPs and Mn (II) ions bring the silver nanoparticles closer, decreasing the interparticle distance and causing slight agglomeration, with a color change from pale yellow to brownish yellow [134].

\subsection{Chromium}

Chromium is a transition metal with oxidation states ranging from $+\mathrm{III}$ and + VI naturally present in rocks, soils, sediments and plants. Among $\mathrm{Cr}$ (VI) and $\mathrm{Cr}$ (III), the first one is more toxic due to its high solubility and mobility in biological systems. In particular, $\mathrm{Cr}$ (VI) is considered to be a severe environmental pollutant due to its highly carcinogenic properties. Colorimetric sensor for the determination of chromium in real water, industrial waste water and vegetable (cauliflower, tomato, spinach, green beans and cabbage) samples was recently reported [135]. Silver nanoparticles were capped with tartaric acid. The plasmon colorimetric sensing of chromium (III and VI) was performed by measuring the change in the SPR band in the UV-visible region of the spectra. The mechanism of the change in the SPR band is related to the aggregation of NPs induced by the coordination complex between chromium ions and tartaric acid present on the surface of NPs. The calibration curve gave a high level of linearity in the range of $5-100 \mu \mathrm{g} / \mathrm{L}$ for $\mathrm{Cr}$ (III) and 10-100 $\mu \mathrm{g} / \mathrm{L}$ for $\mathrm{Cr}(\mathrm{VI})$, respectively. The limits of detection for Cr (III) and Cr (VI) were found to be $2 \mu \mathrm{g} / \mathrm{L}$ and $3 \mu \mathrm{g} / \mathrm{L}$. 
An alternative colorimetric optical sensors based on AgNPs for the detection of hexavalent chromium and ammonia using bio-fabrication in a single step Durenta erecta fruit extract synthesis was recently reported [136]. In this case the kinetic shift of the maximum absorption band and change in color for both $\mathrm{Cr}$ (VI) and ammonia was found to be extremely fast (few seconds). Such a colorimetric sensor shows a high sensitivity and a detection limit up to $0.1 \mathrm{ppm}$.

\subsection{Cobalt}

Cobalt is beneficial for humans because it is a part of vitamin $B_{12}$, which is essential for human health, however too high concentrations of cobalt may be dangerous. Recently, silver nanoparticles capped with 3-mercapto-1propanesulfonic acid sodium salt able to detect Ni (II) or Co (II) in water solution, have been reported. This system is based on the change of the intensity and shape of optical absorption peak due to the surface plasmon resonance when the capped NPs are in presence of metals ions in a water solution. Sensitivity to Ni (II) and Co (II) up to 500 parts per billion (ppb) was found and for a concentration of 1 part per million (ppm), the change in the optical absorption is strong enough to produce a colorimetric effect visible with naked eye. The mechanism responsible for the AgNPs interaction with $\mathrm{Ni}$ (II) and Co (II) (in the range of 0.5-2.0 ppm) looks like based on the coordination compounds formation [112].

Glutathione-AgNPs with spherical shape shows a high sensitivity for all of the metal ions (Ni (II), $\mathrm{Co}$ (II), Cd (II), Pb (II), and As (III)) but poor selective recognition for target metal ions. Whereas, solution containing rod-type AgNPs has a special response to Co (II), and its selective detection might be based on the cooperative effect of cetyltriammonium bromide and glutathione. Therefore, $\mathrm{Co}$ (II) ions could be selectively recognized using rod-type glutathione based AgNPs [137].

A colorimetric assay has been developed for facile, rapid and sensitive detection of Co (II) using dopamine dithiocarbamate (DDTC) functionalized silver nanoparticles. The presence of Co (II) induces the aggregation of AgNPs through coordinate covalent bonds between the catechol groups of DDTC on the surface of AgNPs and cobalt ions, resulting in a color change from bright yellow to reddish. The analytical response is linear in the range from 1.0 to $15 \mathrm{mM}$ with a detection limit of $14 \mu \mathrm{M}$ [138].

\subsection{Cadmium}

Cadmium, a non-essential element for life, is widely used in fertilizers, pesticides, batteries, pigments and coating of steel and various alloys, resulting in the widespread contamination of air, soil, and water. Moreover, cadmium has been recognized as a highly toxic heavy metal ion and is listed by the US Environmental Protection Agency, Disease Registry, and Agency for Toxic Substances as one of the superior pollutants. It accumulates in the human body with a long biological half-life of two to three decades. As a consequence of the food chain system, cadmium exposure can cause many diseases.

Functionalized AgNPs demonstrated to be good systems also for the Cd (II) ions detection. For example, a colorimetric assay has been developed for facile, rapid, and sensitive detection of Cd (II) using 1- amino-2-naphthol-4-sulfonic acid functionalized silver nanoparticles. The presence of Cd (II) induces the aggregation of the NPs through cooperative metal-ligand interaction. As a result, the characteristic surface plasmon resonance peak at $390 \mathrm{~nm}$ was red shifted to $580 \mathrm{~nm}$, yielding a color change from bright yellow to reddish-brown. A good linear relationship was obtained in the range of 1.0-10 $\mu \mathrm{M}$ with a detection limit of $87 \mathrm{nM}$ [139].

An alternative method for the $\mathrm{Cd}$ (II) detection is the one based on the change of the fluorescence of silver NPs [140]. Octamethoxyresorcin arene tetrahydrazide-reduced and stabilized silver nanoparticles were synthesized via a simple one-pot method. The fluorescence intensity of the system was inversely proportional to the cadmium concentration. Using such a selective and sensitive fluorescent probe, cadmium can be detected at a minimum concentration level of $10^{-8} \mathrm{M}$ in a facile way of fluorescence quenching ("turn off" mechanism). This method has been successfully applied for determination of $\mathrm{Cd}$ (II) ions in groundwater and industrial wastewater samples. 
Another example of colorimetric determination of Cd (II) by using silver nanoparticles has been reported by Dong et al. [141]. They capped AgNPs with chalcone carboxylic acid as an optical indicator probe. The addition of Cd (II) ions causes particle aggregation and this is accompanied by a color change from yellow to orange. This assay enables selective detection of Cd (II), while other metal ions do not significantly interfere. The visually detectable limit of detection is $0.23 \mu \mathrm{M}$, and the instrumental detection limit is $0.13 \mu \mathrm{M}$. A linear relationship, for Cd (II) concentration was obtained in the range 0.227 to $3.18 \mu \mathrm{M}$.

\subsection{Lead}

Lead ions are highly toxic heavy-metal ions that can cause serious environmental and health problems and are ubiquitous in industry. Extensive studies have indicated that humans, especially children, can suffer permanent neurological damage and behavioral dysfunction when exhibiting even low blood levels of lead.

A simple and sensitive colorimetric method for the determination of $\mathrm{Pb}$ (II) ions in aqueous samples was developed using 1-(2-mercaptoethyl)-1,3,5-triazinane-2,4,6-trione-functionalized silver $\mathrm{NPs}$. The $\mathrm{Pb}$ (II) ion acted as the metal center of the coordination complex, which formed $\mathrm{N}-\mathrm{Pb}$ (II)-O coordination bonds with the AgNPs, shortening the interparticle distance and inducing NP aggregation. This aggregation resulted in a dramatic color change from yellow to dark blue. The selectivity and sensitivity were noticeably improved in the $\mathrm{pH}$ range of $7-8$, at which a more obvious color change was observed. The sensor exhibited a linear correlation with $\mathrm{Pb}$ (II) ion concentrations within the linear range of $0.1-0.6 \mu \mathrm{g} / \mathrm{mL}$, and the limits of detection in tap and pond water were 0.02 and $0.06 \mu \mathrm{g} / \mathrm{mL}$, respectively [142].

Another approach is based on gluconate-functionalized silver nanoparticles. The functionalized NPs were found to be anionic and resulted to be a chemosensor probe for $\mathrm{Pb}$ (II). They bind selectively $\mathrm{Pb}$ (II) in aqueous solution over other metal ions). Binding results in aggregation of particles and leads to quenching of surface plasmon band intensity at $395 \mathrm{~nm}$ and subsequently appearing of a band at $524 \mathrm{~nm}$. The phenomenon results color change of the solution. The developed system is simple and highly sensitive to detect $\mathrm{Pb}$ (II) ions colorimetrically with limit of detection of about $0.2 \mu \mathrm{M}$ [143].

\subsection{Pesticides}

The term pesticide broadly covers a wide range of compounds including insecticides, fungicides, herbicides, rodenticides, molluscicides, nematicides, plant growth regulators and other chemicals. Despite their many benefits for the improvement of agriculture food production, they can cause short-term adverse health effects, called acute effects, as well as chronic adverse effects that can occur months or years after exposure. Examples of acute health effects include stinging eyes, rashes, blisters, blindness, nausea, dizziness, diarrhea and even death. For these reasons and, because they are largely diffuse in agriculture, it is important to be able to detect them even in very small amounts. Silver NPs systems with specific functionalization can be employed as pesticide colorimetric sensors. Some examples are the following.

A simple and highly sensitive chemiluminescent sensor array for the discrimination of organophosphate and carbamate pesticides was reported by He et al. [144]. The sensor array is based on simultaneous utilization of the triple-channel properties of the luminol-functionalized silver nanoparticle and a $\mathrm{H}_{2} \mathrm{O}_{2}$ chemiluminescent system. The triple-channel properties can be simultaneously altered after interaction with pesticides, producing distinct response patterns as "fingerprints" related to each specific pesticide, which was subjected to principal component analysis to generate a clustering map. Five organophosphate and carbamate pesticides, including dimethoate, dipterex, carbaryl, chlorpyrifos and carbofuran, have been well-distinguished at a concentration of $24 \mu \mathrm{g} / \mathrm{mL}$. Twenty unknown pesticide samples have been successfully identified with an accuracy of $95 \%$.

A novel and rapid method of analysis for organophosphorus pesticides was developed using dipterex as a typical example. Citrate-capped silver nanoparticles and acetylthiocholine were employed 
for the functionalization. The latter compound can be catalyzed by acetylcholinesterase to form thiocholine, which induces the aggregation of AgNPs. As a result, the color of AgNPs in solution changes from bright yellow to pink, and the UV-Vis characteristic absorption peak of AgNPs at about $400 \mathrm{~nm}$ decreases and simultaneously, a new absorption band appears at about $520 \mathrm{~nm}$. The color change is reported in Figure 10. The optical response was found to be linearly related to the concentration of dipterex in the range of $0.25-37.5 \mathrm{ng} / \mathrm{mL}$ with a detection limit of $0.18 \mathrm{ng} / \mathrm{mL}$ [145]. Sensing mechanism is based on the aggregation of the NPs. In particular, TEM images (not reported here) indicated that the AgNPs are well-dispersed with a mean particle diameter of $16.9 \mathrm{~nm}$. After addition of pesticide the TEM image indicated that a large number of AgNPs had aggregated and combined to form a net containing the AgNPs.

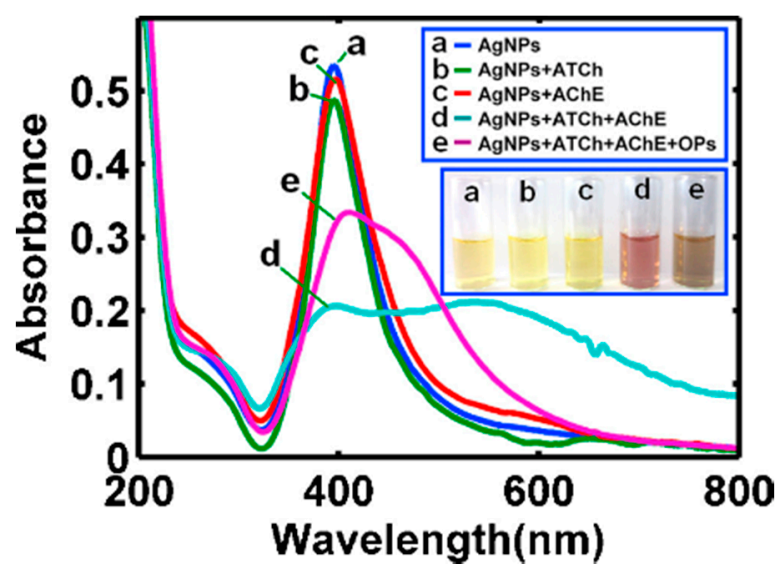

Figure 10. UV-vis absorption spectra of dispersed AgNPs (a), AgNPs with acetylthiocholine (b), AgNPs with acetylcholinesterase (c), AgNPs with acetylthiocholine and acetylcholinesterase (d), AgNPs with acetylthiocholine and acetylcholinesterase in presence of dipterex (e). Each of the samples was heated in a water bath at $37 \circ \mathrm{C}$ for $15 \mathrm{~min}$ before analysis. Inset: corresponding photo images of the reaction solutions after equilibration at $37 \circ \mathrm{C}$ for $15 \mathrm{~min}$ (Reference. [145]).

Rohit et al., developed a simple colorimetric method for on-site analysis of thiram and paraquat using cyclen dithiocarbamate-functionalized silver NPs as a colorimetric probe. The surface functionalized AgNPs are able to encapsulate thiram and paraquat selectively via "host-guest" chemistry, resulting in red-shift of the surface plasmon resonance peak and color change from yellow to pink for thiram and to orange for paraquat, which can be appreciated by the naked eye. The system shows good linearity in the range of $10.0-20.0 \mu \mathrm{M}$ and of $50.0-250 \mu \mathrm{M}$ with limits of detection $2.81 \times 10^{-6} \mathrm{M}$ and $7.21 \times 10^{-6} \mathrm{M}$ for thiram and paraquat, respectively [146].

A colorimetric method for the sensitive and selective detection of the fungicide carbendazim in water and food samples using 4-aminobenzenethiol-functionalized silver nanoparticles has been developed [147]. The system can bind carbendazim through strong ion-pairing and $\pi-\pi$ interactions that causes to form a large conjugate network, resulting in a color change from yellow to orange. The sensor shows a linear behavior in the range of 10-100 $\mu \mathrm{M}$, with a LOD of $1.04 \mu \mathrm{M}$. This colorimetric method has been successfully utilized to detect carbendazim in environmental water and food samples.

Another simple colorimetric assay was developed for the selective detection of glyphosate in water and food samples via the aggregation of 2-mercapto-5-nitrobenzimidazole (MNBZ) capped silver nanoparticles using Mg (II) ions as a tuner and trigger [148]. Initially, AgNPs were synthesized with sodium borohydrate as a reducing agent and capped with MNBZ which showed a yellow color. The addition of $\mathrm{Mg}$ (II) ions did not cause aggregation of MNBZ-Ag NPs, but the subsequent addition of glyphosate resulted a drastic decrease in interparticle distance through complex formation between MNBZ-AgNPs-Mg (II) ion and glyphosate, yielding a color change from yellow to orange-red. Sensitive and selective detection of glyphosate was achieved with a limit of detection of $17.1 \mathrm{nM}$. 
This system was successfully applied to detect glyphosate in water and food samples, demonstrating a good on-site monitoring of glyphosate in agriculture samples.

A sensor for determination of carbamate pesticides based on rhodamine B modified silver nanoparticle was recently reported by Luo et al. [149]. This system combines colorimetric with fluorescence. Carbamate pesticides can inhibit the activity of acetylcholinesterase, thus preventing the generation of thiocholine. On the other hand, thiocholine can transform the yellow silver NPs solutions to gray color and unquenches the fluorescence of rhodamine B simultaneously. Once the activity of acetylcholinesterase was inhibited by the pesticide, the color of the solution remains yellow and the fluorescence of rhodamine B remains quenched. The absorption and fluorescence spectra as a function of carbaryl concentration are reported in Figure 11. Carbaryl was detected in a concentration range from 0.1 to $8.0 \mathrm{ng} / \mathrm{L}$ with a detection limit of $0.023 \mathrm{ng} / \mathrm{L}$. This simple method is suitable for determination of carbamate pesticides in complex samples, such as tomato, apple and river water.

(a)
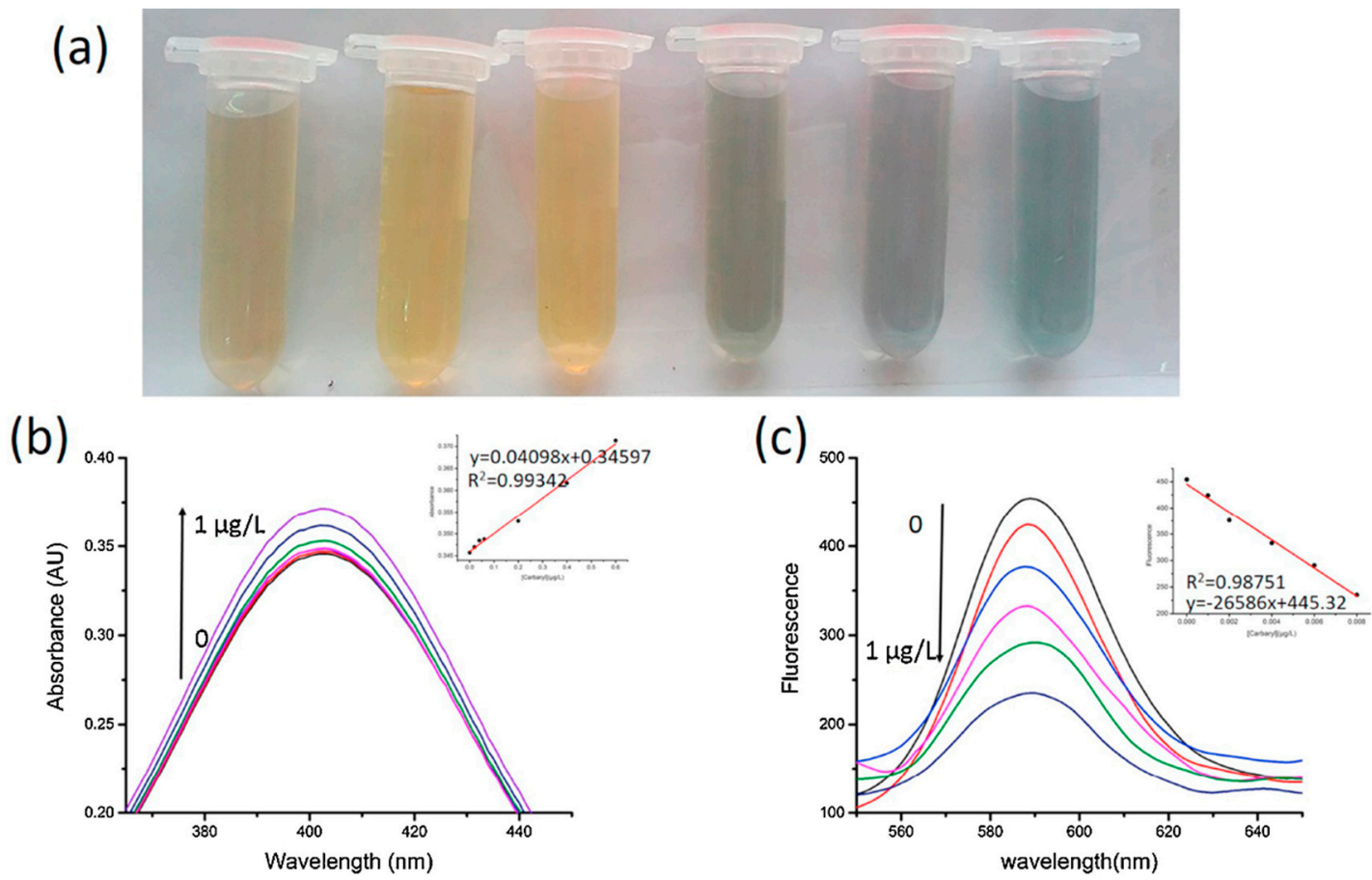

Figure 11. (a) Color change with decreasing concentrations of carbaryl from left to right (1-0.001 mg/L). (b and c) After addition of different concentration of carbaryl, a linear regression model was constructed. The UV-Vis and fluorescence methods were under the optimization condition (Reference. [149]).

A nanosensor based on highly stable AgNPs conjugated with polystyrene-block-poly(2-vinyl pyridine) copolymer demonstrated to be an efficient colorimetric sensor for thiocarbamate pesticide, cartap [150]. The system allowed for rapid and quantitative detection of cartap in concentration range of $0.036-0.36 \mu \mathrm{g} / \mathrm{L}$ with detection limit as low as $0.06 \mu \mathrm{g} / \mathrm{L}$. The sensor efficiently detected cartap in presence of other interfering pesticides and demonstrated great potential for in situ detection of cartap in water and blood plasma.

A novel method for the detection of dimethoate based on the peroxidase-like activity of silver NPs-modified oxidized multiwalled carbon nanotubes (AgNPs/oxMWCNTs) has been developed [151]. The system showed excellent peroxidase-like catalytic activity in hydrogen peroxide-Amplex red (AR) system (AR is oxidized to resorufin, with the resorufin fluorescence at $584 \mathrm{~nm}$ being used to monitor the catalytic activity). After dimethoate was added to AgNPs/oxMWCNTs, the interaction between dimethoate and the AgNPs inhibited the catalytic activity of AgNPs/oxMWCNTs. The decrease in fluorescence was used for the detection of dimethoate in the range of $0.01-0.35 \mu \mathrm{g} / \mathrm{mL}$ with LOD of 
$0.003 \mu \mathrm{g} / \mathrm{mL}$. This method exhibited good selectivity for the detection of dimethoate even in the presence of a high concentration of other pesticides.

A highly sensitive, rapid and low-cost colorimetric monitoring of malathion (an organophosphate insecticide) employing a basic hexapeptide, malathion specific aptamer (oligonucleotide) and silver nanoparticles as a nanoprobe has been reported by Bala et al. [152] Ag NPs are made to interact with the aptamer and peptide to give different optical responses depending upon the presence or absence of malathion. The nanoparticles remain yellow in color in the absence of malathion owing to the binding of aptamer with peptide. In the presence of malathion, the agglomeration of the particles occurs which turns the solution orange. The colorimetric sensor exhibited excellent selectivity and a limit of detection of $0.5 \mathrm{pM}$.

Another colorimetric sensor based on AgNPs capped with thioglycolic acid was recently developed for the detection of 6-benzylaminopurine (6-BAP) [153]. The sensor mechanism of the functionalized AgNPs is based on the binding of 6-BAP through hydrogen-bonding and $\pi-\pi$ bonding that causes large conjugate clusters, resulting in a color change from yellow to reddish orange. A linear relationship for optical absorption for 6-BAP concentration was found in the range of 4-26 $\mu \mathrm{M}$. The detection limit of 6-BAP was $0.2 \mu \mathrm{M}$, which is lower than the other analytical techniques.

A final example that we would like to report, is a colorimetric probe proposed for detection of prothioconazole based on aggregation of unmodified AgNPs [154]. A linear relationship between the concentration of prothioconazole and the absorbance ratio of A500/A395 was found over the range of 0.01 to $0.4 \mu \mathrm{g} / \mathrm{mL}$ with a quantification limit as low as $1.7 \mathrm{ng} / \mathrm{mL}$. In addition, Ag NPs color change from yellow to pink-orange in presence of prothioconazole, indicates highly sensitive naked-eye colorimetric assay for quantifying prothioconazole in real applications. Figure 12 reports the optical absorption and the linear behavior of the system as a function of the contaminant concentration. The proposed approach was successfully used for the determination of prothioconazole in wheat flour and paddy water sample.

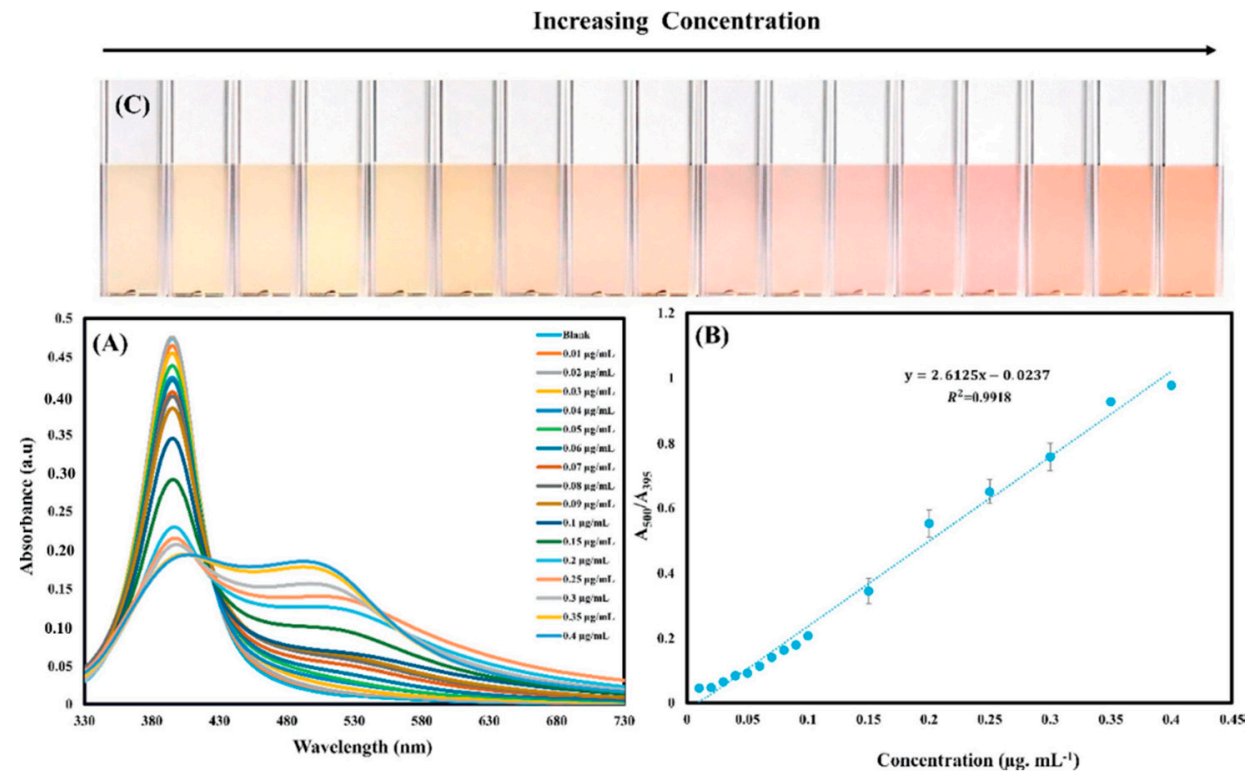

Figure 12. AgNPs UV-vis spectra (A) and linear calibration curve (B) and color ladder for the colorimetric detection of prothioconazole with the common photograph of AgNPs solution (C) in presence of different concentrations of prothioconazole [154].

Tables 2 and 3 present some of the results obtained in the last years in the field of colorimetric optical sensors based on AgNPs for heavy metal ions and pesticides. 
Table 2. List of AgNPs systems as optical sensors for heavy metal ion detection: size and sensing features.

\begin{tabular}{|c|c|c|c|c|c|}
\hline MNPs System & $\begin{array}{c}\text { Size [nm] } \\
\text { (Technique) }\end{array}$ & Response to & Linear Range & LOD & Reference. \\
\hline AgNPs@MBO & $\sim 20$ (TEM) & $\mathrm{Hg}$ (II) & $0-835 \mathrm{ppt}$ & $9.2 \mathrm{pM}$ & [122] \\
\hline AgNPs@MBI & $\sim 20$ (TEM) & $\mathrm{Hg}$ (II) & $0-2760 \mathrm{ppt}$ & $46 \mathrm{pM}$ & [122] \\
\hline AgNPs@MBT & $\sim 20$ (TEM) & $\mathrm{Hg}$ (II) & $0-3294 \mathrm{ppt}$ & $92 \mathrm{pM}$ & [122] \\
\hline AgNPRs@ $\mathrm{C}_{12} \mathrm{H}_{25} \mathrm{SH}$ & $\sim 15-20$ (TEM) & $\mathrm{Hg}$ (II) & $10-500 \mathrm{nM}$ & $3.3 \mathrm{nM}$ & [116] \\
\hline AgNPs@2-aminopyrimidine-4,6-diol & 18 (TEM) & $\mathrm{Hg}$ (II) & $10-50 \mu \mathrm{M}$ & $0.35 \mu \mathrm{M}$ & [115] \\
\hline AgNPs@ citrate and L-cysteine & $5 \pm 2$ (TEM) & $\mathrm{Hg}$ (II) & $1-7.5 \mathrm{ppm}$ & $0.6 \mathrm{ppm}$ & [79] \\
\hline AgNPS@starch & $15.4 \pm 3.9$ (TEM) & $\mathrm{Hg}$ (II) & $4.5-2500 \mathrm{nM}$ & $4.5 \mathrm{nM}$ & [125] \\
\hline AgNPs@gelatin & 8.6 (TEM) & $\mathrm{Hg}$ (II) & $1.25 \mathrm{pM}-125 \mathrm{nM}$ & $25 \mathrm{nM}$ & [126] \\
\hline AgNPs@Dahlia pinnata & 15 (TEM) & $\mathrm{Hg}$ (II) & $0-120 \mu \mathrm{M}$ & - & [71] \\
\hline AgNTs@Citrate & 40.3 (TEM) & $\mathrm{Ni}$ (II) & $0-30 \mu \mathrm{M}$ & $21.6 \mathrm{nM}$ & [127] \\
\hline AgNPs@GSH & 8.0 (TEM) & $\mathrm{Ni}(\mathrm{II})$ & $1 \mu \mathrm{M}-1 \mathrm{mM}$ & $7.5 \mu \mathrm{M}$ & [128] \\
\hline AgNPs@ Adenosine monophosphate/sodium dodecyl sulfonate & $9.8 \pm 3.5(\mathrm{TEM})$ & $\mathrm{Ni}(\mathrm{II})$ & $4-60 \mu \mathrm{M}$ & $0.60 \mu \mathrm{M}$ & [129] \\
\hline AgNPs@3MPS & $5 \pm 2(\mathrm{DLS})$ & $\mathrm{Ni}$ (II) & $0.1-1 \mathrm{ppm}$ & $0.3 \mathrm{ppm}$ & [96] \\
\hline AgNPs@casein-peptide & $20 \pm 2$ (TEM) & $\mathrm{Cu}$ (II) & $0.08-1.44 \mu \mathrm{M}$ & $0.16 \mu \mathrm{M}$ & [130] \\
\hline AgNPs@3,4-dihydroxy-L-phenylalanine & 20 (TEM) & $\mathrm{Cu}(\mathrm{II})$ & $65-125 \mu \mathrm{M}$ & $94 \mu \mathrm{M}$ & [131] \\
\hline AgNPs@3,4-dihydroxy-L-phenylalanine & 20 (TEM) & $\mathrm{Pb}$ (II) & $65-125 \mu \mathrm{M}$ & $81 \mu \mathrm{M}$ & [131] \\
\hline AgNPs@Riboflavin & 20 (DLS) & $\mathrm{Cu}$ (II) & $5-100 \mu \mathrm{M}$ & $1.12 \mathrm{nM}$ & [99] \\
\hline AgNPs@Chitosan & 15 (TEM) & $\mathrm{Fe}$ (III) & $1-500 \mu \mathrm{M}$ & $0.53 \mu \mathrm{M}$ & [113] \\
\hline AgNPs@ N-acetyl-L-cysteine & $6.55 \pm 1.0$ (TEM) & $\mathrm{Fe}$ (III) & $80 \mathrm{nM}-80 \mathrm{mM}$ & $80 \mathrm{nM}$ & [132] \\
\hline AgNPs@ Starch & $15.4 \pm 3.9$ (TEM) & $\mathrm{Fe}(\mathrm{III})$ & $0.7-7 \mathrm{mg} / \mathrm{L}$ & $0.1 \mathrm{mg} / \mathrm{L}$ & [133] \\
\hline AgNPs@L-Tyrosine & $8.2 \pm 2(\mathrm{TEM})$ & $\mathrm{Hg}$ (II) & $16-660 \mathrm{nM}$ & $16 \mathrm{nM}$ & [70] \\
\hline AgNPs@L-Tyrosine & $8.2 \pm 2$ (TEM) & $\mathrm{Mn}$ (II) & $16-500 \mathrm{nM}$ & $16 \mathrm{nM}$ & [70] \\
\hline AuNPs@L-Tyrosine & $17 \pm 2$ (TEM) & $\mathrm{Hg}$ (II) & $33-300 \mathrm{nM}$ & $53 \mathrm{nM}$ & [70] \\
\hline AuNPs@L-Tyrosine & $17 \pm 2($ TEM $)$ & $\mathrm{Pb}$ (II) & $16-100 \mathrm{nM}$ & $16 \mathrm{nM}$ & [70] \\
\hline NPs@Tartaric acid & $6.0 \pm 0.8$ (DLS) & $\mathrm{Cr}$ (III) & $5-100 \mu \mathrm{g} / \mathrm{L}$ & $2 \mu \mathrm{g} / \mathrm{L}$ & [135] \\
\hline NPs@Tartaric acid & $6.0 \pm 0.8$ (DLS) & $\mathrm{Cr}(\mathrm{VI})$ & $10-100 \mu \mathrm{g} / \mathrm{L}$ & $3 \mu \mathrm{g} / \mathrm{L}$ & [135] \\
\hline AgNPs@Durenta erecta & $\sim 23 \pm 4$ (FE-SEM) & $\mathrm{Cr}(\mathrm{VI})$ & $10-100 \mathrm{ppm}$ & $0.1 \mathrm{ppm}$ & [136] \\
\hline AgNPs@3MPS & $4.1 \pm 0.4(\mathrm{TEM})$ & Co (II) & $0.5-2.0 \mathrm{ppm}$ & - & [112] \\
\hline AgNPs@3MPS & $4.1 \pm 0.4(\mathrm{TEM})$ & $\mathrm{Ni}$ (II) & $0.5-1.5 \mathrm{ppm}$ & - & [112] \\
\hline AgNPs@1- amino-2-naphthol-4-sulfonic acid & 12 (DLS) & $\mathrm{Cd}(\mathrm{II})$ & $1-10 \mu \mathrm{M}$ & $87 \mathrm{nM}$ & [139] \\
\hline AgNPs@ Octamethoxy resorcin arene tetrahydrazide & 5 (TEM) & $\mathrm{Cd}$ (II) & $0-10 \mu \mathrm{M}$ & $10 \mathrm{nM}$ & [140] \\
\hline AgNPs@Chalcone carboxyl acid & $\sim 7$ (TEM) & $\mathrm{Cd}$ (II) & $0.227-3.18 \mu \mathrm{M}$ & $0.13 \mu \mathrm{M}$ & [141] \\
\hline AgNPs@1-(2-mercaptoethyl)-1,3,5-triazinane-2,4,6-trione & 10 (TEM) & $\mathrm{Pb}$ (II) & $0.1-0.6 \mu \mathrm{g} / \mathrm{mL}$ & $0.06 \mu \mathrm{g} / \mathrm{mL}$ (tap water) & [142] \\
\hline AgNPs@Gluconate & $9.57 \pm 2($ TEM $)$ & $\mathrm{Pb}$ (II) & $0.5-2.0 \mu \mathrm{M}$ & $0.2029 \mu \mathrm{M}$ & [143] \\
\hline
\end{tabular}

Table 3. List of AgNPs systems as optical sensors for pesticides detection: size and sensing features.

\begin{tabular}{|c|c|c|c|c|c|}
\hline MNPs System & $\begin{array}{c}\text { Size [nm] } \\
\text { (Technique) }\end{array}$ & Response to & Linear Range & LOD & Reference. \\
\hline AgNPs@Luminol $/ \mathrm{H}_{2} \mathrm{O}_{2}$ & $\sim 15$ (TEM) & $\begin{array}{l}\text { Dimethoate, dipterex, carbaryl, } \\
\text { chlorpyrifos and carbofuran }\end{array}$ & - & $24 \mu \mathrm{g} / \mathrm{mL}$ & [144] \\
\hline AgNPs@Citrate/Acetylthiocholine & 16.9 (TEM) & Dipterex & $0.25-37.5 \mathrm{ng} / \mathrm{mL}$ & $\begin{array}{c}0.18 \\
\mathrm{ng} / \mathrm{mL}\end{array}$ & [145] \\
\hline AgNPs@cyclen-dithiocarbamate & 6.0 (DLS) & Thiram & $10.0-20.0 \mu \mathrm{M}$ & $2.81 \mu \mathrm{M}$ & [146] \\
\hline AgNPs@cyclen-dithiocarbamate & 6.0 (DLS) & Paraquat & $50.0-250 \mu \mathrm{M}$ & $7.21 \mu \mathrm{M}$ & [146] \\
\hline AgNPs@4-aminobenzenethiol & 6.5 (TEM) & Carbendazim & $10-100 \mu \mathrm{M}$ & $1.04 \mu \mathrm{M}$ & [147] \\
\hline AgNPs@2-mercapto-5-nitrobenzimidazole/Mg2+ & $\sim 7.2$ (TEM) & Glyphosate & $0.1-1.2 \mu \mathrm{M}$ & $17.1 \mathrm{nM}$ & [148] \\
\hline AgNPs@Rhodamine B & 20 (TEM) & Carbaryl & $0.1-8 \mathrm{ng} / \mathrm{L}$ & $0.023 \mathrm{ng} / \mathrm{L}$ & [149] \\
\hline AgNPs@ polystyrene-block-poly(2-vinyl pyridine) & $104.2 \pm 0.68$ (DLS) & Cartap & $0.036-0.36 \mu \mathrm{g} / \mathrm{L}$ & $0.06 \mu \mathrm{g} / \mathrm{L}$ & [150] \\
\hline AgNPs@oxMWCNTs & 37 (TEM) & Dimethoate & $0.01-0.035 \mu \mathrm{g} / \mathrm{L}$ & $0.003 \mu \mathrm{g} / \mathrm{L}$ & [151] \\
\hline AgNPs@aptamer & - & Malathion & $0.01-0.75 \mathrm{nM}$ & $0.5 \mathrm{pM}$ & [152] \\
\hline AgNPs@Thioglycolic acid & 12 (TEM) & 6-Benzyl aminopurine & $4-26 \mu \mathrm{M}$ & $0.2 \mu \mathrm{M}$ & [153] \\
\hline AgNPs@Trisodium citrate & $\sim 15$ (DLS) & Prothio- conazole & $0.01-0.4 \mu \mathrm{g} / \mathrm{mL}$ & $1.7 \mathrm{ng} / \mathrm{mL}$ & [154] \\
\hline
\end{tabular}

\section{Conclusions}

Silver nanoparticles, thanks to the rapid development of technologies for their versatile chemical synthesis and their characteristics such as stability, tunable monolayers, functional flexibility and low cost, represent promising new optical sensing materials for water pollutants. Their different functionalities allow them to achieve a variety of objectives that can be modulated by tuning their size, shape, structure and optical properties. So far, different approaches have been studied, offering opportunities in water treatments and involving different optical features, all this with the aim 
of obtaining efficient, sensitive and selective sensors, so that they can also be used synergistically. Although many studies have been made using AgNPs as colorimetric sensors, the panorama is complex: as the parameters of size, shape and surface functionalization vary, the silver nanoparticles show different behaviors, selectivity and sensitivity. This however seems more an advantage than a limitation and pushes research to overcome the current limits of LOD and to experiment with new functionalizations, also towards emerging pollutants. In fact, new emerging types of water pollutants, such as hormones, represent new challenges of concern. To respond to these challenges, new nanomaterials must be designed. High expectations are placed on composite materials, where, for example, silver-based nanomaterials can be combined with other materials, for example polymers, or with bioactive molecules, such as enzymes or antibodies. Research fields are always in development. In this context, our review summarizes the recent literature about the synthesis and applications of functionalized silver nanoparticles used as colorimetric sensing materials for the main water pollutants, such as heavy metals and pesticides, to provide readers with a clear and updated guide to the subject.

Author Contributions: Conceptualization, original draft preparation, review and editing: P.P., L.B. and I.V.; supervision, I.V. All authors have read and agreed to the published version of the manuscript.

Funding: This research received no external funding.

Acknowledgments: The Grant of Excellence Departments, MIUR (ARTICOLO 1, COMMI 314-337 LEGGE 232/2016), is gratefully acknowledged by Iole Venditti. Paolo Prosposito gratefully acknowledges the funding of Regione Lazio, through Progetto di ricerca 85-2017-15125, according to L.R.13/08.

Conflicts of Interest: The authors declare no conflict of interest.

\section{References}

1. Giraldo, J.P.; Wu, H.; Newkirk, G.M.; Kruss, S. Nanobiotechnology approaches for engineering smart plant sensors. Nat. Nanotechnol. 2019, 14, 541-553. [CrossRef] [PubMed]

2. Burratti, L.; De Matteis, F.; Casalboni, M.; Francini, R.; Pizzoferrato, R.; Prosposito, P. Polystyrene photonic crystals as optical sensors for volatile organic compounds. Mater. Chem. Phys. 2018, 212, 274-281. [CrossRef]

3. De Angelis, R.; D'Amico, L.; Casalboni, M.; Hatami, F.; Masselink, W.T.; Prosposito, P. Photoluminescence sensitivity to methanol vapours of surface InP quantum dot: Effect of dot size and coverage. Sens. Actuators B Chem. 2013, 189, 113-117. [CrossRef]

4. De Angelis, R.; Casalboni, M.; Hatami, F.; Ugur, A.; Masselink, W.T.; Prosposito, P. Vapour sensing properties of InP quantum dot luminescence. Sens. Actuators B Chem. 2012, 162, 149-152. [CrossRef]

5. Li, N.; Zhao, P.; Astruc, D. Anisotropic Gold Nanoparticles: Synthesis, Properties, Applications, and Toxicity. Angew. Chem. Int. Ed. 2014, 53, 1756-1789. [CrossRef]

6. Burratti, L.; Ciotta, E.; Bolli, E.; Kaciulis, S.; Casalboni, M.; De Matteis, F.; Garzón-Manjón, A.; Scheu, C.; Pizzoferrato, R.; Prosposito, P. Fluorescence enhancement induced by the interaction of silver nanoclusters with lead ions in water. Colloids Surf. A Physicochem. Eng. Asp. 2019, 579, 123634. [CrossRef]

7. Ma, Y.; Zhu, Y.; Liu, B.; Quan, G.; Cui, L. Colorimetric Determination of Hypochlorite Based on the Oxidative Leaching of Gold Nanorods. Materials (Basel) 2018, 11, 1629. [CrossRef]

8. Burratti, L.; Bolli, E.; Casalboni, M.; De Matteis, F.; Mochi, F.; Francini, R.; Casciardi, S.; Prosposito, P. Synthesis of fluorescent ag nanoclusters for sensing and imaging applications. Materials Science Forum 2018, 941, 2243-2248. [CrossRef]

9. Jiang, D.; Pang, J.; You, Q.; Liu, T.; Chu, Z.; Jin, W. Simultaneous biosensing of catechol and hydroquinone via a truncated cube-shaped Au/PBA nanocomposite. Biosens. Bioelectron. 2019, 124-125, 260-267. [CrossRef]

10. Burratti, L.; Casalboni, M.; De Matteis, F.; Pizzoferrato, R.; Prosposito, P. Polystyrene opals responsive to methanol vapors. Materials (Basel) 2018, 11, 1547. [CrossRef]

11. Pantalei, S.; Zampetti, E.; Macagnano, A.; Bearzotti, A.; Venditti, I.; Russo, M. Enhanced Sensory Properties of a Multichannel Quartz Crystal Microbalance Coated with Polymeric Nanobeads. Sensors 2007, 7, 2920-2928. [CrossRef] [PubMed]

12. Bearzotti, A.; MacAgnano, A.; Pantalei, S.; Zampetti, E.; Venditti, I.; Fratoddi, I.; Vittoria Russo, M. Alcohol vapor sensory properties of nanostructured conjugated polymers. J. Phys. Condens. Matter 2008, 20. [CrossRef] 
13. Venditti, I.; Fratoddi, I.; Bearzotti, A. Self-assembled copolymeric nanoparticles as chemically interactive materials for humidity sensors. Nanotechnology 2010, 21, 355502. [CrossRef] [PubMed]

14. Wang, Y.; Yan, B.; Chen, L. SERS Tags: Novel Optical Nanoprobes for Bioanalysis. Chem. Rev. 2013, 113, 1391-1428. [CrossRef]

15. D'Amato, R.; Venditti, I.; Russo, M.V.; Falconieri, M. Growth control and long-range self-assembly of poly(methyl methacrylate) nanospheres. J. Appl. Polym. Sci. 2006, 102, 4493-4499. [CrossRef]

16. Luo, C.; Wang, Y.; Li, X.; Jiang, X.; Gao, P.; Sun, K.; Zhou, J.; Zhang, Z.; Jiang, Q. An Optical Sensor with Polyaniline-Gold Hybrid Nanostructures for Monitoring $\mathrm{pH}$ in Saliva. Nanomaterials 2017, 7, 67. [CrossRef]

17. Ciotta, E.; Prosposito, P.; Tagliatesta, P.; Lorecchio, C.; Stella, L.; Kaciulis, S.; Soltani, P.; Placidi, E.; Pizzoferrato, R. Discriminating between different heavy metal ions with fullerene-derived nanoparticles. Sensors (Switzerland) 2018, 18, 1496. [CrossRef]

18. De Angelis, R.; Venditti, I.; Fratoddi, I.; De Matteis, F.; Prosposito, P.; Cacciotti, I.; D'Amico, L.; Nanni, F.; Yadav, A.; Casalboni, M.; et al. From nanospheres to microribbons: Self-assembled Eosin Y doped PMMA nanoparticles as photonic crystals. J. Colloid Interface Sci. 2014, 414, 24-32. [CrossRef]

19. Lamastra, F.R.; De Angelis, R.; Antonucci, A.; Salvatori, D.; Prosposito, P.; Casalboni, M.; Congestri, R.; Melino, S.; Nanni, F. Polymer composite random lasers based on diatom frustules as scatterers. RSC Adv. 2014, 4, 61809-61816. [CrossRef]

20. Barettin, D.; De Angelis, R.; Prosposito, P.; Auf Der Maur, M.; Casalboni, M.; Pecchia, A. Model of a realistic InP surface quantum dot extrapolated from atomic force microscopy results. Nanotechnology 2014, 25. [CrossRef]

21. Salvato, M.; Scagliotti, M.; De Crescenzi, M.; Crivellari, M.; Prosposito, P.; Cacciotti, I.; Castrucci, P. Single walled carbon nanotube/Si heterojunctions for high responsivity photodetectors. Nanotechnology 2017, 28, 435201. [CrossRef] [PubMed]

22. Ciotta, E.; Prosposito, P.; Pizzoferrato, R. Positive curvature in Stern-Volmer plot described by a generalized model for static quenching. J. Lumin. 2019, 206, 518-522. [CrossRef]

23. Shah, A.A.; Umar, A.A.; Salleh, M.M. Efficient quantum capacitance enhancement in DSSC by gold nanoparticles plasmonic effect. Electrochim. Acta 2016, 195, 134-142. [CrossRef]

24. Bonomo, M.; Naponiello, G.; Venditti, I.; Zardetto, V.; Di Carlo, A.; Dini, D. Electrochemical and photoelectrochemical properties of screen-printed nickel oxide thin films obtained from precursor pastes with different compositions. J. Electrochem. Soc. 2017, 164, H137-H147. [CrossRef]

25. Saravanan, S.; Kato, R.; Balamurugan, M.; Kaushik, S.; Soga, T. Efficiency improvement in dye sensitized solar cells by the plasmonic effect of green synthesized silver nanoparticles. J. Sci. Adv. Mater. Devices 2017, 2, 418-424. [CrossRef]

26. Barettin, D.; Di Carlo, A.; De Angelis, R.; Casalboni, M.; Prosposito, P. Effect of dielectric Bragg grating nanostructuring on dye sensitized solar cells. Opt. Express 2012, 20, A888. [CrossRef]

27. Narayan, N.; Meiyazhagan, A.; Vajtai, R. Metal nanoparticles as green catalysts. Materials (Basel) 2019, 12, 3602. [CrossRef]

28. Palomo, J.M.; Filice, M. Biosynthesis of metal nanoparticles: Novel efficient heterogeneous nanocatalysts. Nanomaterials 2016, 6, 84. [CrossRef]

29. Rossi, A.; Donati, S.; Fontana, L.; Porcaro, F.; Battocchio, C.; Proietti, E.; Venditti, I.; Bracci, L.; Fratoddi, I. Negatively charged gold nanoparticles as a dexamethasone carrier: Stability in biological media and bioactivity assessment: In vitro. RSC Adv. 2016, 6, 99016-99022. [CrossRef]

30. Vinci, G.; Rapa, M. Noble metal nanoparticles applications: Recent trends in food control. Bioengineering 2019, 6, 10. [CrossRef]

31. Venditti, I. Morphologies and functionalities of polymeric nanocarriers as chemical tools for drug delivery: A review. J. King Saud Univ. Sci. 2019, 31, 398-411. [CrossRef]

32. Wei, L.; Lu, J.; Xu, H.; Patel, A.; Chen, Z.-S.; Chen, G. Silver nanoparticles: Synthesis, properties, and therapeutic applications. Drug Discov. Today 2015, 20, 595-601. [CrossRef]

33. Fratoddi, I.; Venditti, I.; Battocchio, C.; Carlini, L.; Amatori, S.; Porchia, M.; Tisato, F.; Bondino, F.; Magnano, E.; Pellei, M.; et al. Highly hydrophilic gold nanoparticles as carrier for anticancer copper(I) complexes: Loading and release studies for biomedical applications. Nanomaterials 2019, 9, 772. [CrossRef] [PubMed] 
34. Venditti, I.; Cartoni, A.; Fontana, L.; Testa, G.; Scaramuzzo, F.A.; Faccini, R.; Terracciano, C.M.; Camillocci, E.S.; Morganti, S.; Giordano, A.; et al. Y3+ embedded in polymeric nanoparticles: Morphology, dimension and stability of composite colloidal system. Colloids Surf. A Physicochem. Eng. Asp. 2017, 532, 125-131. [CrossRef]

35. Venditti, I. Engineered gold-based nanomaterials: Morphologies and functionalities in biomedical applications. a mini review. Bioengineering 2019, 6, 53. [CrossRef] [PubMed]

36. Shimizu, F.M.; Braunger, M.L.; Riul, A. Heavy Metal/Toxins Detection Using Electronic Tongues. Chemosensors 2019, 7, 36. [CrossRef]

37. Maccora, D.; Dini, V.; Battocchio, C.; Fratoddi, I.; Cartoni, A.; Rotili, D.; Castagnola, M.; Faccini, R.; Bruno, I.; Scotognella, T.; et al. Gold nanoparticles and nanorods in nuclear medicine: A mini review. Appl. Sci. 2019, 9, 3232. [CrossRef]

38. Jeyaraj, M.; Rajesh, M.; Arun, R.; MubarakAli, D.; Sathishkumar, G.; Sivanandhan, G.; Dev, G.K.; Manickavasagam, M.; Premkumar, K.; Thajuddin, N.; et al. An investigation on the cytotoxicity and caspase-mediated apoptotic effect of biologically synthesized silver nanoparticles using Podophyllum hexandrum on human cervical carcinoma cells. Colloids Surf. B Biointerfaces 2013, 102, 708-717. [CrossRef] [PubMed]

39. Fratoddi, I.; Cartoni, A.; Venditti, I.; Catone, D.; O’Keeffe, P.; Paladini, A.; Toschi, F.; Turchini, S.; Sciubba, F.; Testa, G.; et al. Gold nanoparticles functionalized by rhodamine B isothiocyanate: A new tool to control plasmonic effects. J. Colloid Interface Sci. 2018, 513, 10-19. [CrossRef]

40. Toh, H.S.; Faure, R.L.; Amin, L.B.M.; Hay, C.Y.F.; George, S. A light-assisted in situ embedment of silver nanoparticles to prepare functionalized fabrics. Nanotechnol. Sci. Appl. 2017, 10, 147-162. [CrossRef]

41. Shellaiah, M.; Sun, K.W. Review on nanomaterial-based melamine detection. Chemosensors 2019, 7, 9. [CrossRef]

42. Rinaldi, F.; del Favero, E.; Moeller, J.; Hanieh, P.N.; Passeri, D.; Rossi, M.; Angeloni, L.; Venditti, I.; Marianecci, C.; Carafa, M.; et al. Hydrophilic Silver Nanoparticles Loaded into Niosomes: Physical-Chemical Characterization in View of Biological Applications. Nanomaterials 2019, 9, 1177. [CrossRef] [PubMed]

43. Porcaro, F.; Carlini, L.; Ugolini, A.; Visaggio, D.; Visca, P.; Fratoddi, I.; Venditti, I.; Meneghini, C.; Simonelli, L.; Marini, C.; et al. Synthesis and structural characterization of silver nanoparticles stabilized with 3-mercapto-1-propansulfonate and 1-thioglucose mixed thiols for antibacterial applications. Materials (Basel) 2016, 9, 1028. [CrossRef]

44. Tharmaraj, V.; Pitchumani, K. Alginate stabilized silver nanocube-Rh6G composite as a highly selective mercury sensor in aqueous solution. Nanoscale 2011, 3, 1166-1170. [CrossRef]

45. Elfassy, E.; Mastai, Y.; Salomon, A. Cysteine sensing by plasmons of silver nanocubes. J. Solid State Chem. 2016, 241, 110-114. [CrossRef]

46. Deen, G.; Chua, V. Synthesis and Properties of New "Stimuli" Responsive Nanocomposite Hydrogels Containing Silver Nanoparticles. Gels 2015, 1, 117-134. [CrossRef] [PubMed]

47. Venditti, I.; Testa, G.; Sciubba, F.; Carlini, L.; Porcaro, F.; Meneghini, C.; Mobilio, S.; Battocchio, C.; Fratoddi, I. Hydrophilic Metal Nanoparticles Functionalized by 2-Diethylaminoethanethiol: A Close Look at the Metal-Ligand Interaction and Interface Chemical Structure. J. Phys. Chem. C 2017, 121, 8002-8013. [CrossRef]

48. Venditti, I. Gold nanoparticles in photonic crystals applications: A review. Materials (Basel) 2017, 10, 97. [CrossRef]

49. Stetsyshyn, Y.; Awsiuk, K.; Kusnezh, V.; Raczkowska, J.; Jany, B.R.; Kostruba, A.; Harhay, K.; Ohar, H.; Lishchynskyi, O.; Shymborska, Y.; et al. Shape-Controlled synthesis of silver nanoparticles in temperature-responsive grafted polymer brushes for optical applications. Appl. Surf. Sci. 2019, 463, 1124-1133. [CrossRef]

50. Lin, H.C.; Su, Y.A.; Liu, T.Y.; Sheng, Y.J.; Lin, J.J. Thermo-responsive nanoarrays of silver nanoparticle, silicate nanoplatelet and PNiPAAm for the antimicrobial applications. Colloids Surf. B Biointerfaces 2017, 152, 459-466. [CrossRef]

51. Wang, X.; Wu, J.; Li, P.; Wang, L.; Zhou, J.; Zhang, G.; Li, X.; Hu, B.; Xing, X. Microenvironment-Responsive Magnetic Nanocomposites Based on Silver Nanoparticles/Gentamicin for Enhanced Biofilm Disruption by Magnetic Field. ACS Appl. Mater. Interfaces 2018, 10, 34905-34915. [CrossRef] [PubMed] 
52. Corsi, P.; Venditti, I.; Battocchio, C.; Meneghini, C.; Bruni, F.; Prosposito, P.; Mochi, F.; Capone, B. Designing an Optimal Ion Adsorber at the Nanoscale: The Unusual Nucleation of AgNP/Co 2+-Ni 2+ Binary Mixtures. J. Phys. Chem. C 2019, 123, 3855-3860. [CrossRef]

53. Wang, Y.; Yang, X.; Bai, J.; Jiang, X.; Fan, G. High sensitivity hydrogen peroxide and hydrazine sensor based on silver nanocubes with rich $\{100\}$ facets as an enhanced electrochemical sensing platform. Biosens. Bioelectron. 2013, 43, 180-185. [CrossRef] [PubMed]

54. Farhadi, K.; Forough, M.; Molaei, R.; Hajizadeh, S.; Rafipour, A. Highly selective Hg 2+ colorimetric sensor using green synthesized and unmodified silver nanoparticles. Sens. Actuators B Chem. 2012, 161, 880-885. [CrossRef]

55. Vilela, D.; González, M.C.; Escarpa, A. Sensing colorimetric approaches based on gold and silver nanoparticles aggregation: Chemical creativity behind the assay. A review. Anal. Chim. Acta 2012, 751, 24-43. [CrossRef]

56. Ratnarathorn, N.; Chailapakul, O.; Henry, C.S.; Dungchai, W. Simple silver nanoparticle colorimetric sensing for copper by paper-based devices. Talanta 2012, 99, 552-557. [CrossRef]

57. Laliwala, S.K.; Mehta, V.N.; Rohit, J.V.; Kailasa, S.K. Citrate-modified silver nanoparticles as a colorimetric probe forsimultaneous detection of four triptan-family drugsSweta. Sens. Actuators B Chem. 2014, 197, 254-263. [CrossRef]

58. Vinod Kumar, V.; Anbarasan, S.; Christena, L.R.; Saisubramanian, N.; Philip Anthony, S. Bio-functionalized silver nanoparticles for selective colorimetric sensing of toxic metal ions and antimicrobial studies. Spectrochim. Acta Part A Mol. Biomol. Spectrosc. 2014, 129, 35-42. [CrossRef]

59. Kailasa, S.K.; Koduru, J.R.; Desai, M.L.; Park, T.J.; Singhal, R.K.; Basu, H. Recent progress on surface chemistry of plasmonic metal nanoparticles for colorimetric assay of drugs in pharmaceutical and biological samples. TrAC Trends Anal. Chem. 2018, 105, 106-120. [CrossRef]

60. Gottschalk, F.; Sun, T.; Nowack, B. Environmental concentrations of engineered nanomaterials: Review of modeling and analytical studies. Environ. Pollut. 2013, 181, 287-300. [CrossRef]

61. Corsi, I.; Cherr, G.N.; Lenihan, H.S.; Labille, J.; Hassellov, M.; Canesi, L.; Dondero, F.; Frenzilli, G.; Hristozov, D.; Puntes, V.; et al. Common strategies and technologies for the ecosafety assessment and design of nanomaterials entering the marine environment. ACS Nano 2014, 8, 9694-9709. [CrossRef] [PubMed]

62. Ma, R.; Levard, C.; Marinakos, S.M.; Cheng, Y.; Liu, J.; Michel, F.M.; Brown, G.E.; Lowry, G.V. Size-controlled dissolution of organic-coated silver nanoparticles. Environ. Sci. Technol. 2012, 46, 752-759. [CrossRef] [PubMed]

63. Hsiao, I.L.; Hsieh, Y.K.; Wang, C.F.; Chen, I.C.; Huang, Y.J. Trojan-horse mechanism in the cellular uptake of silver nanoparticles verified by direct intra- and extracellular silver speciation analysis. Environ. Sci. Technol. 2015, 49, 3813-3821. [CrossRef] [PubMed]

64. Courtois, P.; Rorat, A.; Lemiere, S.; Guyoneaud, R.; Attard, E.; Levard, C.; Vandenbulcke, F. Ecotoxicology of silver nanoparticles and their derivatives introduced in soil with or without sewage sludge: A review of effects on microorganisms, plants and animals. Environ. Pollut. 2019, 253, 578-598. [CrossRef]

65. Minetto, D.; Volpi Ghirardini, A.; Libralato, G. Saltwater ecotoxicology of Ag, Au, CuO, TiO2, ZnO and C60 engineered nanoparticles: An overview. Environ. Int. 2016, 92-93, 189-201. [CrossRef]

66. McGillicuddy, E.; Murray, I.; Kavanagh, S.; Morrison, L.; Fogarty, A.; Cormican, M.; Dockery, P.; Prendergast, M.; Rowan, N.; Morris, D. Silver nanoparticles in the environment: Sources, detection and ecotoxicology. Sci. Total Environ. 2017, 575, 231-246. [CrossRef]

67. Kołątaj, K.; Krajczewski, J.; Kudelski, A. Plasmonic nanoparticles for environmental analysis. Environ. Chem. Lett. 2020. [CrossRef]

68. D'Amato, R.; Medei, L.; Venditti, I.; Russo, M.V.; Falconieri, M. Chemical synthesis of polyphenylacetylene nanospheres with controlled dimensions for photonic crystals. Mater. Sci. Eng. C 2003, 23, 861-865. [CrossRef]

69. Muhammed Ajmal, C.; Faseela, K.P.; Singh, S.; Baik, S. Hierarchically-structured silver nanoflowers for highly conductive metallic inks with dramatically reduced filler concentration. Sci. Rep. 2016, 6, 1-9. [CrossRef]

70. Annadhasan, M.; Muthukumarasamyvel, T.; Sankar Babu, V.R.; Rajendiran, N. Green synthesized silver and gold nanoparticles for colorimetric detection of $\mathrm{Hg} 2+, \mathrm{Pb} 2+$, and $\mathrm{Mn} 2+$ in aqueous medium. ACS Sustain. Chem. Eng. 2014, 2, 887-896. [CrossRef]

71. Roy, K.; Sarkar, C.K.; Ghosh, C.K. Rapid colorimetric detection of $\mathrm{Hg} 2+$ ion by green silver nanoparticles synthesized using Dahlia pinnata leaf extract. Green Process. Synth. 2015, 4, 455-461. [CrossRef]

72. Roy, S. Binding behaviors of greenly synthesized silver nanoparticles - Lysozyme interaction: Spectroscopic approach. J. Mol. Struct. 2018, 1154, 145-151. [CrossRef] 
73. Burmistrova, N.A.; Kolontaeva, O.A.; Duerkop, A. New nanomaterials and luminescent optical sensors for detection of hydrogen peroxide. Chemosensors 2015, 3, 253-273. [CrossRef]

74. Salinas, C.I.; Bracamonte, A.G. Design of advanced smart ultraluminescent multifunctional nanoplatforms for biophotonics and nanomedicine applications. Front. Drug Chem. Clin. Res. 2018, 1, 1-8. [CrossRef]

75. Balasooriya, E.R.; Jayasinghe, C.D.; Jayawardena, U.A.; Ruwanthika, R.W.D.; De Silva, R.M.; Udagama, P.V. Honey Mediated Green Synthesis of Nanoparticles: New Era of Safe Nanotechnology. J. Nanomater. 2017, 2017. [CrossRef]

76. Suzuki, Y. Development of fluorescent reagent based on ligand exchange reaction for the highly sensitive and selective detection of dopamine in the serum. Sensors (Switzerland) 2019, 19, 3928. [CrossRef] [PubMed]

77. Ortega-Liebana, M.C.; Bonet-Aleta, J.; Hueso, J.L.; Santamaria, J. Gold-Based Nanoparticles on Amino-Functionalized Mesoporous Silica Supports as Nanozymes for Glucose Oxidation. Catalysts 2020, 10, 333. [CrossRef]

78. Pinelli, F.; Perale, G.; Rossi, F. Coating and Functionalization Strategies for Nanogels and Nanoparticles for Selective Drug Delivery. Gels 2020, 6, 6. [CrossRef] [PubMed]

79. Prosposito, P.; Burratti, L.; Bellingeri, A.; Protano, G.; Faleri, C.; Corsi, I.; Battocchio, C.; Iucci, G.; Tortora, L.; Secchi, V.; et al. Bifunctionalized Silver Nanoparticles as $\mathrm{Hg} 2+$ Plasmonic Sensor in Water: Synthesis, Characterizations, and Ecosafety. Nanomaterials 2019, 9, 1353. [CrossRef]

80. Roto, R.; Mellisani, B.; Kuncaka, A.; Mudasir, M.; Suratman, A. Colorimetric sensing of Pb2+ ion by using ag nanoparticles in the presence of dithizone. Chemosensors 2019, 7, 28. [CrossRef]

81. Lu, Y.; Wu, C.; Wu, Y.; You, R.; Lin, G.; Chen, Y.; Feng, S. Ag-coated cellulose fibers as Surface-enhanced Raman scattering substrates for adsorptive detection of malachite green. Materials (Basel) 2018, 11, 1197. [CrossRef] [PubMed]

82. Mikhailova, M.E.; Senchukova, A.S.; Lezov, A.A.; Gubarev, A.S.; Trützschler, A.K.; Schubert, U.S.; Tsvetkov, N.V. Stabilization of silver nanoparticles by cationic aminoethyl methacrylate copolymers in aqueous media-Effects of component ratios and molar masses of copolymers. Polymers (Basel) 2019, 11, 1647. [CrossRef] [PubMed]

83. Wang, Y.; Dong, X.; Zhao, L.; Xue, Y.; Zhao, X.; Li, Q.; Xia, Y. Facile and Green Fabrication of Carrageenan-Silver Nanoparticles for Colorimetric Determination of Cu2+ and S2-. Nanomaterials 2020, 10, 83. [CrossRef] [PubMed]

84. Tang, J.; Xiong, P.; Cheng, Y.; Chen, Y.; Peng, S.; Zhu, Z.Q. Enzymatic oxydate-triggered AgNPs etching: A novel signal-on photoelectrochemical immunosensing platform based on Ag@AgCl nanocubes loaded RGO plasmonic heterostructure. Biosens. Bioelectron. 2019, 130, 125-131. [CrossRef] [PubMed]

85. Xue, Y.; Ma, L.; Zhang, L.; Zhao, W.; Li, Z.; Li, Q. A Green, Rapid and Efficient Dual-Sensors for Highly Selective and Sensitive Detection of Cation ( $\mathrm{Hg} 2+)$ and Anion (S2-) Ions Based on CMS/AgNPs Composites. Polymers (Basel) 2020, 12, 113. [CrossRef] [PubMed]

86. Yuan, D.; Li, H.; Zhu, W.; He, F.; Xu, Y.; Meng, X.; Zhang, W.; Fang, X.; Ding, T. Broad emission spectral enhancement of polyfluorene copolymer by coupling to assembled plasmonic crystal of silver nanocubes. Thin Solid Films 2020, 695, 137763. [CrossRef]

87. Tegegne, W.A.; Mekonnen, M.L.; Beyene, A.B.; Su, W.N.; Hwang, B.J. Sensitive and reliable detection of deoxynivalenol mycotoxin in pig feed by surface enhanced Raman spectroscopy on silver nanocubes@polydopamine substrate. Spectrochim. Acta Part A Mol. Biomol. Spectrosc. 2020, 229, 117940. [CrossRef]

88. Joseph, D.; Huh, Y.S.; Han, Y.K. A top-down chemical approach to tuning the morphology and plasmon resonance of spiky nanostars for enriched SERS-based chemical sensing. Sens. Actuators B Chem. 2019, 288, 120-126. [CrossRef]

89. Sitjar, J.; Liao, J.D.; Lee, H.; Pan, L.P.; Liu, B.H.; Fu, W.E.; Chen, G.D. Ag nanostructures with spikes on adhesive tape as a flexible sers-active substrate for in situ trace detection of pesticides on fruit skin. Nanomaterials 2019, 9, 1750. [CrossRef]

90. Tsai, Y.T.; Chang, S.J.; Ji, L.W.; Hsiao, Y.J.; Tang, I.T.; Lu, H.Y.; Chu, Y.L. High Sensitivity of NO Gas Sensors Based on Novel Ag-Doped ZnO Nanoflowers Enhanced with a UV Light-Emitting Diode. ACS Omega 2018, 3, 13798-13807. [CrossRef] 
91. Pham, T.B.; Hoang, T.H.C.; Pham, V.H.; Nguyen, V.C.; Nguyen, T.V.; Vu, D.C.; Pham, V.H.; Bui, H. Detection of Permethrin pesticide using silver nano-dendrites SERS on optical fibre fabricated by laser-assisted photochemical method. Sci. Rep. 2019, 9, 12590. [CrossRef] [PubMed]

92. Bi, J. Electrodeposited silver nanoflowers as sensitive surface-enhanced Raman scattering sensing substrates. Mater. Lett. 2019, 236, 398-402. [CrossRef]

93. Luan, V.H.; Han, J.H.; Kang, H.W.; Lee, W. Ultra-sensitive non-enzymatic amperometric glucose sensors based on silver nanowire/graphene hybrid three-dimensional nanostructures. Results Phys. 2019, 15, 102761. [CrossRef]

94. Zhang, M.; Wang, M.; Zhang, M.; Qiu, L.; Liu, Y.; Zhang, W.; Zhang, Y.; Hu, J.; Wu, G. Flexible and highly sensitive humidity sensor based on sandwich-like $\mathrm{Ag} / \mathrm{Fe} 3 \mathrm{O} 4$ nanowires composite for multiple dynamic monitoring. Nanomaterials 2019, 9, 1399. [CrossRef]

95. Firdaus, M.L.; Aprian, A.; Meileza, N.; Hitsmi, M.; Elvia, R.; Rahmidar, L.; Khaydarov, R. Smartphone coupled with a paper-based colorimetric device for sensitive and portable mercury ion sensing. Chemosensors 2019, 7, 25. [CrossRef]

96. Prosposito, P.; Mochi, F.; Ciotta, E.; Casalboni, M.; De Matteis, F.; Venditti, I.; Fontana, L.; Testa, G.; Fratoddi, I. Hydrophilic silver nanoparticles with tunable optical properties: Application for the detection of heavy metals in water. Beilstein J. Nanotechnol. 2016, 7, 1654-1661. [CrossRef]

97. Krajczewski, J.; Kołątaj, K.; Kudelski, A. Plasmonic nanoparticles in chemical analysis. RSC Adv. 2017, 7, 17559-17576. [CrossRef]

98. Khatoon, U.T.; Rao, G.V.S.N.; Mantravadi, K.M.; Oztekin, Y. Strategies to synthesize various nanostructures of silver and their applications-A review. RSC Adv. 2018, 8, 19739-19753. [CrossRef]

99. Basiri, S.; Mehdinia, A.; Jabbari, A. Biologically green synthesized silver nanoparticles as a facile and rapid label-free colorimetric probe for determination of $\mathrm{Cu} 2+$ in water samples. Spectrochim. Acta Part A Mol. Biomol. Spectrosc. 2017, 171, 297-304. [CrossRef]

100. Mukherjee, T.; Ghosh, G.; Mukherjee, R.; Das, T.K. Study of arsenic (III) removal by monolayer protected silver nanoadsorbent and its execution on prokaryotic system. J. Environ. Manage. 2019, 244, 440-452. [CrossRef]

101. Jarujamrus, P.; Meelapsom, R.; Pencharee, S.; Obma, A.; Amatatongchai, M.; Ditcharoen, N.; Chairam, S.; Tamuang, S. Use of a smartphone as a colorimetric analyzer in paper-based devices for sensitive and selective determination of mercury in water samples. Anal. Sci. 2018, 34, 75-81. [CrossRef] [PubMed]

102. Oliveira, M.J.; Quaresma, P.; Peixoto de Almeida, M.; Araújo, A.; Pereira, E.; Fortunato, E.; Martins, R.; Franco, R.; Águas, H. Office paper decorated with silver nanostars - an alternative cost effective platform for trace analyte detection by SERS. Sci. Rep. 2017, 7, 2480. [CrossRef]

103. Mayer, K.M.; Hafner, J.H. Localized Surface Plasmon Resonance Sensors. Chem. Rev. 2011, 111, 3828-3857. [CrossRef] [PubMed]

104. Maier, S.A. Plasmonics: Fundamentals and Applications; Springer US: New York, NY, USA, 2007; ISBN 978-0-387-33150-8.

105. Mie, G. Beiträge zur Optik trüber Medien, speziell kolloidaler Metallösungen. Ann. Phys. 1908, 330, $377-445$. [CrossRef]

106. Gans, R. Über die Form ultramikroskopischer Goldteilchen. Ann. Phys. 1912, 342, 881-900. [CrossRef]

107. Zhao, J.; Pinchuk, A.O.; McMahon, J.M.; Li, S.; Ausman, L.K.; Atkinson, A.L.; Schatz, G.C. Methods for Describing the Electromagnetic Properties of Silver and Gold Nanoparticles. Acc. Chem. Res. 2008, 41, 1710-1720. [CrossRef]

108. Underwood, S.; Mulvaney, P. Effect of the Solution Refractive Index on the Color of Gold Colloids. Langmuir 1994, 10, 3427-3430. [CrossRef]

109. Huang, T.; Xu, X.-H.N. Synthesis and characterization of tunable rainbow colored colloidal silver nanoparticles using single-nanoparticle plasmonic microscopy and spectroscopy. J. Mater. Chem. 2010, 20, 9867. [CrossRef]

110. Mehta, V.N.; Rohit, J.V.; Kailasa, S.K. Functionalization of silver nanoparticles with 5-sulfoanthranilic acid dithiocarbamate for selective colorimetric detection of $\mathrm{Mn}^{2+}$ and $\mathrm{Cd}^{2+}$ ions. New J. Chem. 2016, 40, 4566-4574. [CrossRef]

111. Qu, F.; Chen, P.; Zhu, S.; You, J. High selectivity of colorimetric detection of p-nitrophenol based on Ag nanoclusters. Spectrochim. Acta Part A Mol. Biomol. Spectrosc. 2017, 171, 449-453. [CrossRef] 
112. Mochi, F.; Burratti, L.; Fratoddi, I.; Venditti, I.; Battocchio, C.; Carlini, L.; Iucci, G.; Casalboni, M.; De Matteis, F.; Casciardi, S.; et al. Plasmonic Sensor Based on Interaction between Silver Nanoparticles and Ni2+ or Co2+ in Water. Nanomaterials 2018, 8, 488. [CrossRef] [PubMed]

113. Tashkhourian, J.; Sheydaei, O. Chitosan capped silver nanoparticles as colorimetric sensor for the determination of iron(III). Anal. Bioanal. Chem. Res. 2017, 4, 249-260. [CrossRef]

114. Nguyen, N.D.; Nguyen, T.V.; Chu, A.D.; Tran, H.V.; Tran, L.T.; Huynh, C.D. A label-free colorimetric sensor based on silver nanoparticles directed to hydrogen peroxide and glucose. Arab. J. Chem. 2018, 11, 1134-1143. [CrossRef]

115. Prasad, K.S.; Shruthi, G.; Shivamallu, C. Functionalized Silver Nano-Sensor for Colorimetric Detection of Hg2+ Ions: Facile Synthesis and Docking Studies. Sensors 2018, 18, 2698. [CrossRef] [PubMed]

116. Chen, L.; Fu, X.; Lu, W.; Chen, L. Highly Sensitive and Selective Colorimetric Sensing of Hg 2+ Based on the Morphology Transition of Silver Nanoprisms. ACS Appl. Mater. Interfaces 2013, 5, 284-290. [CrossRef]

117. Liu, Y.; Huang, C.Z. Real-Time Dark-Field Scattering Microscopic Monitoring of the in Situ Growth of Single Ag@Hg Nanoalloys. ACS Nano 2013, 7, 11026-11034. [CrossRef]

118. Bhattacharjee, Y.; Chakraborty, A. Label-Free Cysteamine-Capped Silver Nanoparticle-Based Colorimetric Assay for $\mathrm{Hg}(\mathrm{II})$ Detection in Water with Subnanomolar Exactitude. ACS Sustain. Chem. Eng. 2014, 2, 2149-2154. [CrossRef]

119. Sarkar, P.K.; Halder, A.; Polley, N.; Pal, S.K. Development of Highly Selective and Efficient Prototype Sensor for Potential Application in Environmental Mercury Pollution Monitoring. Water Air Soil Pollut. 2017, 228, 314. [CrossRef]

120. Wei, H.; Hossein Abtahi, S.M.; Vikesland, P.J. Plasmonic colorimetric and SERS sensors for environmental analysis. Environ. Sci. Nano 2015, 2, 120-135. [CrossRef]

121. Amin, M.T.; Alazba, A.A.; Manzoor, U. A Review of Removal of Pollutants from Water/Wastewater Using Different Types of Nanomaterials. Adv. Mater. Sci. Eng. 2014, 2014, 1-24. [CrossRef]

122. Bhattacharjee, Y.; Chatterjee, D.; Chakraborty, A. Mercaptobenzoheterocyclic compounds functionalized silver nanoparticle, an ultrasensitive colorimetric probe for $\mathrm{Hg}$ (II) detection in water with picomolar precision: A correlation between sensitivity and binding affinity. Sens. Actuators B Chem. 2018, 255, 210-216. [CrossRef]

123. Roy, B.; Bairi, P.; Nandi, A.K. Selective colorimetric sensing of mercury(ii) using turn off-turn on mechanism from riboflavin stabilized silver nanoparticles in aqueous medium. Analyst 2011, 136, 3605. [CrossRef] [PubMed]

124. Fernández-Lodeiro, J.; Núñez, C.; Oliveira, E.; Capelo, J.L.; Lodeiro, C. 1D chain fluorescein-functionalized gold and silver nanoparticles as new optical mercury chemosensor in aqueous media. J. Nanoparticle Res. 2013, 15, 1828. [CrossRef]

125. Vasileva, P.; Alexandrova, T.; Karadjova, I. Application of Starch-Stabilized Silver Nanoparticles as a Colorimetric Sensor for Mercury(II) in 0.005 mol/L Nitric Acid. J. Chem. 2017, 2017, 1-9. [CrossRef]

126. Jeevika, A.; Shankaran, D.R. Functionalized silver nanoparticles probe for visual colorimetric sensing of mercury. Mater. Res. Bull. 2016, 83, 48-55. [CrossRef]

127. Yoon, S.J.; Nam, Y.S.; Lee, H.J.; Lee, Y.; Lee, K.B. Colorimetric probe for Ni2+ based on shape transformation of triangular silver nanoprisms upon $\mathrm{H} 2 \mathrm{O} 2$ etching. Sens. Actuators B Chem. 2019, 300, 127045. [CrossRef]

128. Li, H.; Cui, Z.; Han, C. Glutathione-stabilized silver nanoparticles as colorimetric sensor for Ni2+ ion. Sensors Actuators B Chem. 2009, 143, 87-92. [CrossRef]

129. Feng, J.; Jin, W.; Huang, P.; Wu, F. Highly selective colorimetric detection of Ni2+ using silver nanoparticles cofunctionalized with adenosine monophosphate and sodium dodecyl sulfonate. J. Nanoparticle Res. 2017, 19, 306. [CrossRef]

130. Ghodake, G.S.; Shinde, S.K.; Saratale, R.G.; Kadam, A.A.; Saratale, G.D.; Syed, A.; Ameen, F.; Kim, D.-Y. Colorimetric detection of $\mathrm{Cu}^{2+}$ based on the formation of peptide-copper complexes on silver nanoparticle surfaces. Beilstein J. Nanotechnol. 2018, 9, 1414-1422. [CrossRef]

131. Cheon, J.Y.; Park, W.H. Green synthesis of silver nanoparticles stabilized with mussel-inspired protein and colorimetric sensing of lead(II) and copper(II) ions. Int. J. Mol. Sci. 2016, 17, 6. [CrossRef]

132. Gao, X.; Lu, Y.; He, S.; Li, X.; Chen, W. Colorimetric detection of iron ions (III) based on the highly sensitive plasmonic response of the N-acetyl-l-cysteine-stabilized silver nanoparticles. Anal. Chim. Acta 2015, 879, 118-125. [CrossRef] [PubMed] 
133. Vasileva, P.; Dobrev, S.; Karadjova, I. Colorimetric detection of iron(III) based on sensitive and selective plasmonic response of starch-coated silver nanoparticles. In International Conference on Quantum, Nonlinear, and Nanophotonics 2019 (ICQNN 2019); Dreischuh, A.A., Neshev, D.N., Staude, I., Spassov, T., Eds.; SPIE: Bellingham, DC, USA, 2019; Volume 2019, p. 17.

134. Narayanan, K.B.; Han, S.S. Colorimetric detection of manganese(II) ions using alginate-stabilized silver nanoparticles. Res. Chem. Intermed. 2017, 43, 5665-5674. [CrossRef]

135. Shrivas, K.; Sahu, S.; Patra, G.K.; Jaiswal, N.K.; Shankar, R. Localized surface plasmon resonance of silver nanoparticles for sensitive colorimetric detection of chromium in surface water, industrial waste water and vegetable samples. Anal. Methods 2016, 8, 2088-2096. [CrossRef]

136. Ismail, M.; Khan, M.I.; Akhtar, K.; Khan, M.A.; Asiri, A.M.; Khan, S.B. Biosynthesis of silver nanoparticles: A colorimetric optical sensor for detection of hexavalent chromium and ammonia in aqueous solution. Phys. E Low-Dimensional Syst. Nanostructures 2018, 103, 367-376. [CrossRef]

137. Sung, H.K.; Oh, S.Y.; Park, C.; Kim, Y. Colorimetric Detection of Co 2+ Ion Using Silver Nanoparticles with Spherical, Plate, and Rod Shapes. Langmuir 2013, 29, 8978-8982. [CrossRef]

138. Mehta, V.N.; Mungara, A.K.; Kailasa, S.K. Dopamine dithiocarbamate functionalized silver nanoparticles as colorimetric sensors for the detection of cobalt ion. Anal. Methods 2013, 5, 1818-1822. [CrossRef]

139. Huang, P.; Liu, B.; Jin, W.; Wu, F.; Wan, Y. Colorimetric detection of Cd2+ using 1-amino-2-naphthol-4-sulfonic acid functionalized silver nanoparticles. J. Nanoparticle Res. 2016, 18, 1-9. [CrossRef]

140. Makwana, B.A.; Vyas, D.J.; Bhatt, K.D.; Darji, S.; Jain, V.K. Novel fluorescent silver nanoparticles: Sensitive and selective turn off sensor for cadmium ions. Appl. Nanosci. 2016, 6, 555-566. [CrossRef]

141. Dong, Y.; Ding, L.; Jin, X.; Zhu, N. Silver nanoparticles capped with chalcon carboxylic acid as a probe for colorimetric determination of cadmium(II). Microchim. Acta 2017, 184, 3357-3362. [CrossRef]

142. Noh, K.C.; Nam, Y.S.; Lee, H.J.; Lee, K.B. A colorimetric probe to determine $\mathrm{Pb} 2+$ using functionalized silver nanoparticles. Analyst 2015, 140, 8209-8216. [CrossRef]

143. Choudhury, R.; Misra, T.K. Gluconate stabilized silver nanoparticles as a colorimetric sensor for $\mathrm{Pb} 2+$. Colloids Surf. A Physicochem. Eng. Asp. 2018, 545, 179-187. [CrossRef]

144. He, Y.; Xu, B.; Li, W.; Yu, H. Silver Nanoparticle-Based Chemiluminescent Sensor Array for Pesticide Discrimination. J. Agric. Food Chem. 2015, 63, 2930-2934. [CrossRef] [PubMed]

145. Li, Z.; Wang, Y.; Ni, Y.; Kokot, S. Unmodified silver nanoparticles for rapid analysis of the organophosphorus pesticide, dipterex, often found in different waters. Sens. Actuators B Chem. 2014, 193, 205-211. [CrossRef]

146. Rohit, J.V.; Kailasa, S.K. Cyclen dithiocarbamate-functionalized silver nanoparticles as a probe for colorimetric sensing of thiram and paraquat pesticides via host-guest chemistry. J. Nanoparticle Res. 2014, 16. [CrossRef]

147. Patel, G.M.; Rohit, J.V.; Singhal, R.K.; Kailasa, S.K. Recognition of carbendazim fungicide in environmental samples by using 4-aminobenzenethiol functionalized silver nanoparticles as a colorimetric sensor. Sens. Actuators B Chem. 2015, 206, 684-691. [CrossRef]

148. Rawat, K.A.; Majithiya, R.P.; Rohit, J.V.; Basu, H.; Singhal, R.K.; Kailasa, S.K. Mg2+ ion as a tuner for colorimetric sensing of glyphosate with improved sensitivity: Via the aggregation of 2-mercapto-5-nitrobenzimidazole capped silver nanoparticles. RSC Adv. 2016, 6, 47741-47752. [CrossRef]

149. Luo, Q.J.; Li, Y.X.; Zhang, M.Q.; Qiu, P.; Deng, Y.H. A highly sensitive, dual-signal assay based on rhodamine B covered silver nanoparticles for carbamate pesticides. Chinese Chem. Lett. 2017, 28, 345-349. [CrossRef]

150. Rahim, S.; Khalid, S.; Bhanger, M.I.; Shah, M.R.; Malik, M.I. Polystyrene-block-poly(2vinylpyridine)-conjugated silver nanoparticles as colorimetric sensor for quantitative determination of Cartap in aqueous media and blood plasma. Sens. Actuators B Chem. 2018, 259, 878-887. [CrossRef]

151. Hsu, C.W.; Lin, Z.Y.; Chan, T.Y.; Chiu, T.C.; Hu, C.C. Oxidized multiwalled carbon nanotubes decorated with silver nanoparticles for fluorometric detection of dimethoate. Food Chem. 2017, 224, 353-358. [CrossRef]

152. Bala, R.; Mittal, S.; Sharma, R.K.; Wangoo, N. A supersensitive silver nanoprobe based aptasensor for low cost detection of malathion residues in water and food samples. Spectrochim. Acta Part A Mol. Biomol. Spectrosc. 2018, 196, 268-273. [CrossRef] 
153. Zheng, M.; He, J.; Wang, Y.; Wang, C.; Ma, S.; Sun, X. Colorimetric recognition of 6-benzylaminopurine in environmental samples by using thioglycolic acid functionalized silver nanoparticles. Spectrochim. Acta Part A Mol. Biomol. Spectrosc. 2018, 192, 27-33. [CrossRef] [PubMed]

154. Ivrigh, Z.J.N.; Fahimi-Kashani, N.; Hormozi-Nezhad, M.R. Aggregation-based colorimetric sensor for determination of prothioconazole fungicide using colloidal silver nanoparticles (AgNPs). Spectrochim. Acta Part A Mol. Biomol. Spectrosc. 2017, 187, 143-148. [CrossRef] [PubMed]

(c)

(C) 2020 by the authors. Licensee MDPI, Basel, Switzerland. This article is an open access article distributed under the terms and conditions of the Creative Commons Attribution (CC BY) license (http://creativecommons.org/licenses/by/4.0/). 